\title{
The role of nitric oxide during embryonic wound healing
}

\author{
Pavel Abaffy ${ }^{1}$, Silvie Tomankova', Ravindra Naraine ${ }^{1}$, Mikael Kubista $^{1,2}$ and Radek Sindelka ${ }^{1 *}$ (D)
}

\begin{abstract}
Background: The study of the mechanisms controlling wound healing is an attractive area within the field of biology, with it having a potentially significant impact on the health sector given the current medical burden associated with healing in the elderly population. Healing is a complex process and includes many steps that are regulated by coding and noncoding RNAs, proteins and other molecules. Nitric oxide (NO) is one of these small molecule regulators and its function has already been associated with inflammation and angiogenesis during adult healing.

Results: Our results showed that NO is also an essential component during embryonic scarless healing and acts via a previously unknown mechanism. NO is mainly produced during the early phase of healing and it is crucial for the expression of genes associated with healing. However, we also observed a late phase of healing, which occurs for several hours after wound closure and takes place under the epidermis and includes tissue remodelling that is dependent on NO. We also found that the NO is associated with multiple cellular metabolic pathways, in particularly the glucose metabolism pathway. This is particular noteworthy as the use of NO donors have already been found to be beneficial for the treatment of chronic healing defects (including those associated with diabetes) and it is possible that its mechanism of action follows those observed during embryonic wound healing.
\end{abstract}

Conclusions: Our study describes a new role of NO during healing, which may potentially translate to improved therapeutic treatments, especially for individual suffering with problematic healing.

Keywords: Xenopus laevis, Nitric oxide, Wound healing, Transcriptome, RNA-sequencing, Leptin, AP-1

\section{Background}

Wound healing and its regulation is an attractive and rapidly developing field of biology and medicine. The importance for the better understanding of wound healing mechanisms and their regulation is getting more attention because of its relation to the increasing number of ageing people [1]. Defects in wound healing have often been associated with the onset of civilization diseases, where it still remains a burden to the medical system $[2,3]$. Therefore, a better comprehension of the wound healing mechanism should lead to the implementation of more effective and cheaper treatments.

The processes of wound healing are very similar amongst different species, ranging from simple organisms like Drosophila to more complex mammals like humans

\footnotetext{
* Correspondence: sindelka@ibt.cas.cz

${ }^{1}$ Institute of Biotechnology of the Czech Academy of Sciences - BIOCEV,

Prumyslova 595, 25250 Vestec, Czech Republic

Full list of author information is available at the end of the article
}

[4]. Two types of wound healing, adult and embryonic, have already been identified. Adult wound healing is a much more complex process than embryonic, and leads to troublesome scar formation. The adult wound healing can be divided into four phases: haemostasis, inflammation, proliferation and remodelling $[5,6]$. Haemostasis starts immediately after the injury. The main purpose of haemostasis is to avoid blood loss. It involves three processes: blood vessel constriction, a formation of a temporary plug by platelets and clotting (coagulation) of blood at the site of damage [7]. The second phase is called the inflammatory phase and it partially overlaps with haemostasis. In this phase, the immune system is activated and inflammatory cells are recruited from the bloodstream [8]. In humans, haemostasis and inflammatory phases typically last from several hours up to several days. The next phase, proliferation, is characterized by an increase in cell proliferation, which is required for the completion of wound closure. The proliferation phase usually takes several days 
or even weeks. The final phase is remodelling, when the wound is closed and a new tissue structure beneath is formed including a scar layer which consists of fibrous material deposits [9].

Contrastingly, multicellular embryonic wound healing has only two phases: fast contraction and migration with wound closure $[10,11]$. Immediately after injury, the cells at the wound edge produce a high level of calcium, which activates phosphorylation of extracellular signal-regulated kinases (ERK). Calcium release is followed by the formation of an actinomyosin ring and wound tissue contraction [12]. This early phase takes about $30 \mathrm{~min}$ and results in about $80 \%$ of wound closure [13]. In the second phase of embryonic healing, filopodial protrusions are formed to complete the wound closure [10,14-17] and de novo gene expression of healing specific genes is induced [18]. During this late phase, production of small and biologically active molecules such as reactive oxygen species (ROS) are observed [19-22].

Comparison of adult and embryonic wound healing processes show similarities, but also differences [4]. The most important aspect of healing in embryos is the ability to heal without a scar. Such a phenomenon was described in many animal species including mammalian embryos before the third trimester of pregnancy [23, 24]. This encourages the importance of studies to elucidate regulation and signalling pathways of embryonic wound healing in order to translate then for use in adult wound therapeutic treatments. Several animal models such as Drosophila, Caenorhabditis and Danio have been introduced in the last decade to elucidate various steps of embryonic wound healing [25-28]. In addition, Xenopus laevis embryos have become a very popular model for epithelial wound healing studies. Different embryonic developmental stages of the Xenopus such as the egg, blastula, gastrula and even later stages have shown relatively similar healing responses including calcium release and actinomyosin ring formation [10, 12, 29-32].

Importance of calcium and ROS production during healing have been shown many times [12, 21, 33-36]. However, only recently the small radical molecule, nitric oxide (NO), have also been implicated as having a role during healing [37, 38]. NO is a gasotransmitter and free radical, that regulates various biological processes. Low levels of NO usually have stimulatory effects on cells during blood pressure regulation [39], proliferation [40], angiogenesis [41] or neurotransmission [42]. In addition, NO has been observed to regulate key processes of adult healing, such as angiogenesis [43], inflammation, cell proliferation, differentiation and apoptosis [44] together with matrix deposition and tissue remodelling [45]. Activity of NO is usually associated with its primary downstream "canonical" pathway. $\mathrm{NO}$ is produced by $\mathrm{NO}$ synthases (NOS) during the conversion of L-arginine to
L-citrulline [46]. The produced NO can then react with the active site of soluble guanylate cyclase (sGC). The activated sGC transforms GTP into cyclic GMP (cGMP). cGMP than activates protein kinase G (PKG, cGMPdependent protein kinase), which phosphorylates various downstream targets, such as myosin light chains phosphatase responsible for different biological process, such as smooth muscle relaxation [47]. In contrast to physiological low NO level and its activity through the canonical cGMP-dependent pathway, high-level NO acts through cGMP-independent pathway and has instead a detrimental effect on cell viability where it also acts as an antibacterial agent stimulating inflammation [48]. At high concentrations, NO reacts with oxygen radicals and forms aggressive molecules of peroxynitrite, which then nitrosylates nitrosates or nitrates different signalling proteins $[49,50]$. For example, this modification leads to a loss of DNA binding capacity of nuclear factor kappalight-chain-enhancer of activated B cells (NF- $\mathrm{kB}$ ), reduction in the regulation of transcription [51] or to the inhibition of the activity of c-Jun N-terminal kinase (JNK) which is used to phosphorylate c-Jun [52].

In our study, we found strong NO production in the wounded tissue of embryos at various developmental stages. Early stages of embryos still lack functional immune and blood systems, which are the main components with known NO activity during adult wound healing. We hypothesized that NO is an important factor also during embryonic wound healing. Here we demonstrated the importance and necessity of NO production during early and late phases of embryonic wound healing and suggest a new mechanism of NO activity by regulation of gene expression of key healing signalling pathways.

\section{Results}

A burst of NO production is a universal response to injury for embryos after the blastula stage

NO production during wound healing was studied using 5,6-Diaminofluorescein diacetate (DAF-2DA) reporter molecule added to media at tailbud (stage 26) and swimming tadpole (stage 41) stages (Fig. 1a). At the stage 26, the production of NO was observed only within the first two layers of cells at the wound edge (Fig. 1b), with the highest production of NO being observed between 15 and $30 \mathrm{~min}$ after injury (Fig. 1c). The NO production increased more than 3.5 times at $15 \mathrm{~min}$ post-wounding (pw) compared to the physiological NO level. The NO production decreased at 30 $\mathrm{min}$ and returns to the physiological level at $60 \mathrm{~min}$ (Fig. 1d). Similar NO production changes were observed after tail amputation (Fig. 1e, f). The highest NO production (more than 6 -fold increase) was observed at 15 min post-amputation (pa). The NO production then 


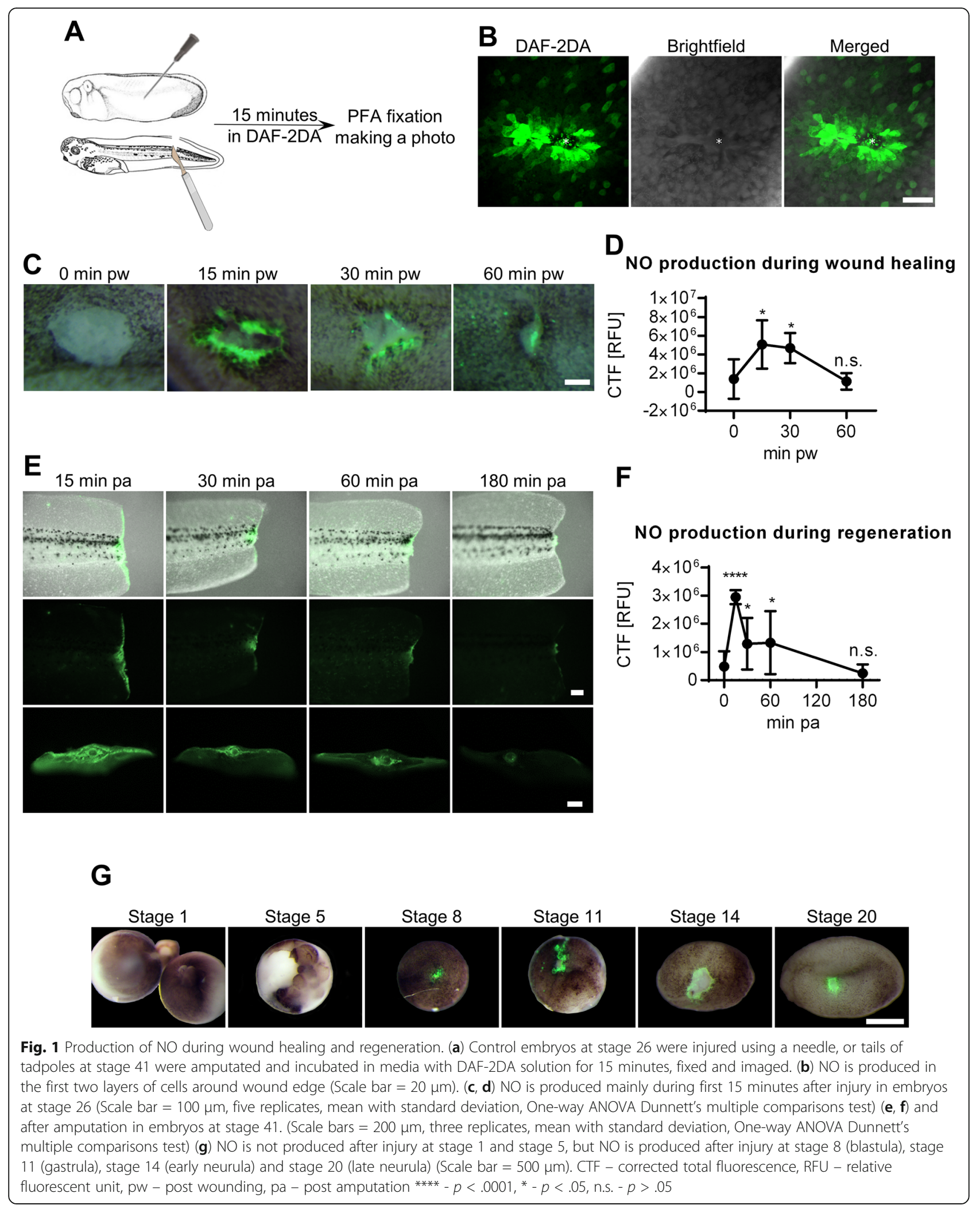


decreased at 30 and $60 \mathrm{~min}$ pa and returned to physiological level at $180 \mathrm{~min}$ pa. Moreover, burst of NO production was observed also during the wound healing at stage 8 (blastula), stage 11 (gastrula) and stages 14-20 (neurula). In contrast, NO production was absent during wound healing of earlier developmental stages such as stage 1 (egg) or stage 5 (Fig. 1g).

\section{NO is crucial for embryonic wound healing}

The importance of $\mathrm{NO}$ production during embryonic wound healing was studied using two complementary tools: a NOS chemical inhibitor called TRIM and gene specific knock down of both nos 1 and nos3. TRIM treatment simulated acute efficient inhibition of $\mathrm{NO}$ production, while nos $1+$ nos3-MOs injection reflected a chronical decrease of NO production (Fig. 2a). In both cases, inhibition of NO production led to phenotypic defects in the wound healing process (Fig. 2b). In the control embryos, the wound size was reduced to $25 \%$ at $30 \mathrm{~min}$ pw and it was fully closed at $90 \mathrm{~min}$ pw (Fig. 2c). Inhibition of NO production led to significantly slower injury closing. During the first $30 \mathrm{~min}$ the wounds closed to only $52 \%$ of size (nos1 + nos3-MOs) and of 85\% size (TRIM treated) of injury area. Wound closing in the embryos with inhibited NO production was almost stopped after $30 \mathrm{~min}$ pw (Fig. 2d). Altogether, results support necessity of NO production especially during early phase of embryonic wound healing.

\section{Embryonic wound healing is regulated by a modest number of genes}

The transcriptome analysis of the healing tissue at the key phases (uninjured tissue (time 0), and 30, 60, $90 \mathrm{~min}$ pw) using tailbud (stage 26) embryos was performed (Fig. 3a, Additional file 1: File S1). In total 23,609 genes were found to be expressed in the dissected healing area.

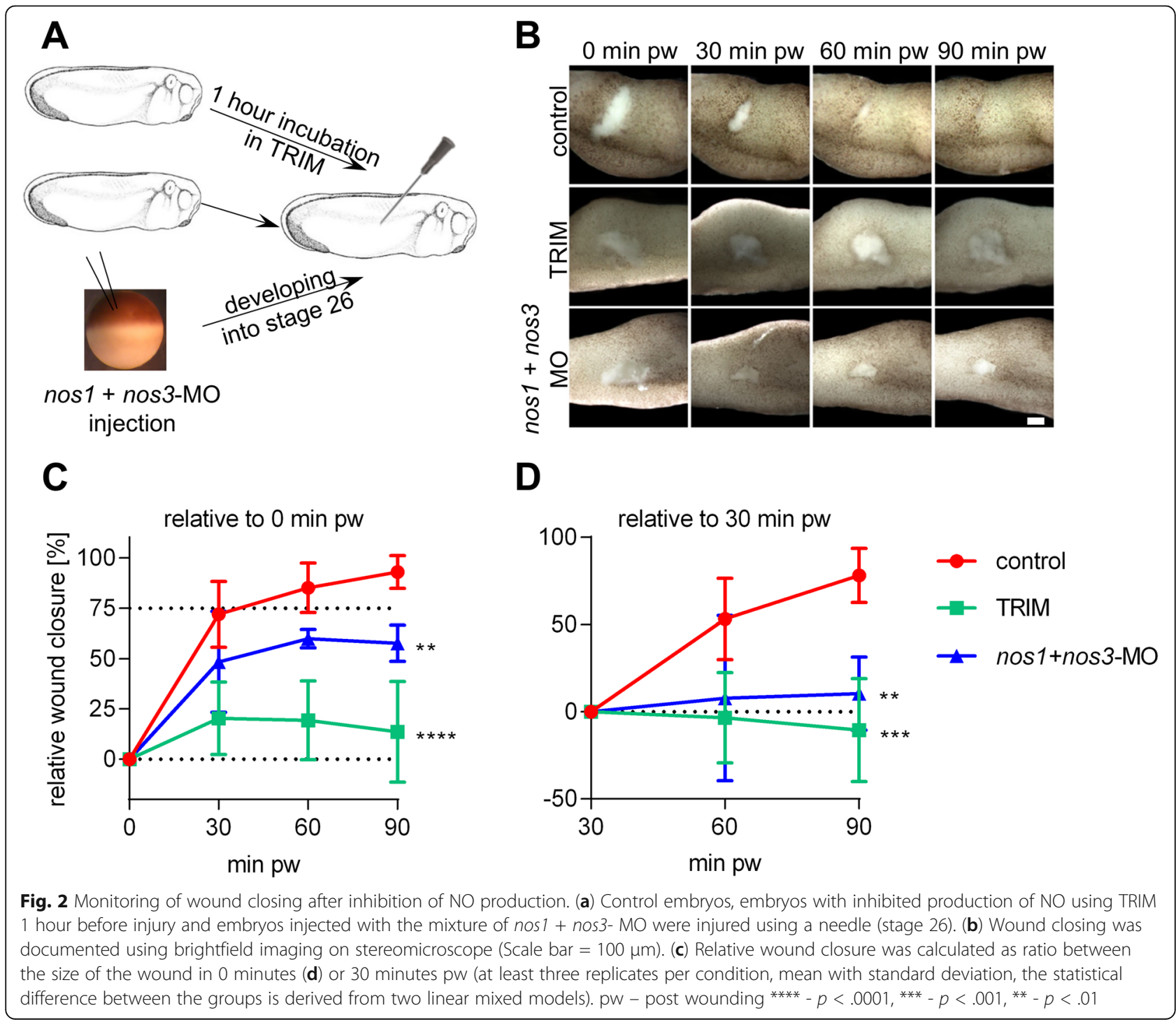


A

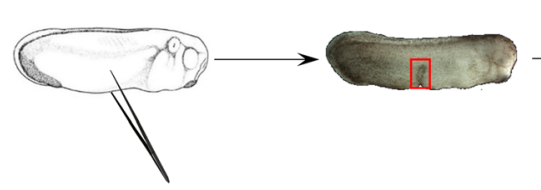

Sample collection

$(0,30,60,90$ minutes $)$

RNA-Seq library

preparation and data

analysis

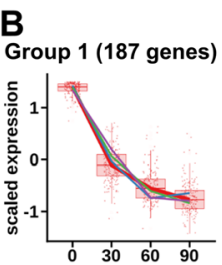

\begin{tabular}{|l|l|c|c|}
\hline \multicolumn{4}{|c|}{ Group 1 $(n=111)$} \\
\hline \multicolumn{1}{|c|}{ GO Term } & \multicolumn{1}{|c|}{ Description } & $\begin{array}{c}\text { FDR } \\
\text { q-value }\end{array}$ & $\begin{array}{c}\text { Enrich- } \\
\text { ment }\end{array}$ \\
\hline GO:0007599 & hemostasis $(n=11)$ & $9.07 E-05$ & 9.58 \\
\hline GO:0006357 & regulation of transcription by RNA polymerase II $(n=34)$ & 0.00115 & 2.46 \\
\hline GO:0048856 & anatomical structure development $(n=45)$ & 0.00245 & 1.97 \\
\hline $\begin{array}{l}\text { Examples of } \\
\text { genes }\end{array}$ & dhh, gata6, bmpr2, gata4, gata5 & & \\
\hline
\end{tabular}

D

\begin{tabular}{|l|l|r|r|}
\hline E & \multicolumn{3}{|c|}{ Group 2 $(\mathbf{n}=\mathbf{6 0 0})$} \\
\hline GO:0042127 & regulation of cell proliferation $(\mathbf{n}=102)$ & $5.87 \mathrm{E}-05$ & 1.78 \\
\hline GO:0010941 & regulation of cell death $(\mathrm{n}=105)$ & $8.03 \mathrm{E}-05$ & 1.73 \\
\hline GO:0042221 & response to chemical $(\mathrm{n}=147)$ & $5.86 \mathrm{E}-05$ & 1.55 \\
\hline $\begin{array}{l}\text { Examples of } \\
\text { genes }\end{array}$ & $b m p 4, f z d 5$, atf3, ddit3, mdh1, aacs, coq10b & \\
\hline
\end{tabular}

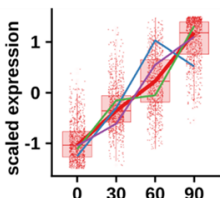

genes

F

Group 3 (177 genes)

\begin{tabular}{|l|l|r|r|}
\hline G & \multicolumn{3}{|c|}{ Group 3 $(\mathbf{n}=\mathbf{9 6})$} \\
\hline GO:0019221 & cytokine-mediated signaling pathway $(\mathrm{n}=24)$ & $2.98 \mathrm{E}-10$ & 7.06 \\
\hline GO:0006952 & defense response $(\mathrm{n}=20)$ & $6.89 \mathrm{E}-05$ & 4.56 \\
\hline GO:0007166 & cell surface receptor signaling pathway $(\mathrm{n}=33)$ & $1.84 \mathrm{E}-04$ & 2.67 \\
\hline GO:0002682 & regulation of immune system process $(\mathrm{n}=22)$ & $2.38 \mathrm{E}-03$ & 3.04 \\
\hline $\begin{array}{l}\text { Examples of } \\
\text { genes }\end{array}$ & lep, mmp8, aqp3, fos/1, cxcl11, nfkbiz, socs1, wnt7a, mmp1 \\
\hline
\end{tabular}



Group 4 (166 genes)

\begin{tabular}{|l|l|r|r|}
\hline I & \multicolumn{3}{|c|}{ Group 4 $(\mathbf{n}=120)$} \\
\hline GO:0032502 & developmental process $(n=71)$ & $3.67 \mathrm{E}-07$ & 1.98 \\
\hline GO:0006357 & regulation of transcription by RNA polymerase II $(\mathrm{n}=43)$ & $2.44 \mathrm{E}-07$ & 2.88 \\
\hline GO:0009653 & anatomical structure morphogenesis $(\mathrm{n}=36)$ & $1.89 \mathrm{E}-07$ & 3.34 \\
\hline $\begin{array}{l}\text { Examples of } \\
\text { genes }\end{array}$ & fos, jun, egr1, klf2, hes1, btg2, bhlhe40, nr4a1 & \\
\hline
\end{tabular}

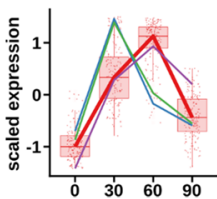

min pw
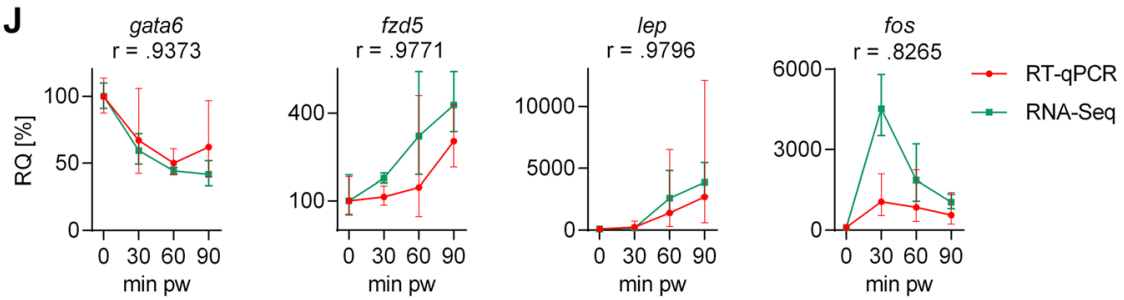

Fig. 3 Global gene expression profiles during embryonic wound healing. (a) Control embryos at stage 26 were injured using forceps and healing tissues were dissected (only the part marked by red rectangle) and collected for RNA-Seq analysis. (b-i) DEGs were grouped based on their expression profile relatively to 0 minutes and $\mathrm{GO}$ analysis was performed. ( $\mathbf{b}, \mathbf{d}, \mathbf{f}, \mathbf{h}$ ) Expression profiles of genes are representative of the log transformed data, average gene expression is shown in red and expression of three representative genes are shown in green, purple and blue. (c, e, $\mathbf{g}$, i) Genes, which have an annotation and human homolog, were used for $\mathrm{GO}$ analysis. Numbers of analysed genes are in the table together with the representative $\mathrm{GO}$ terms for each group. (j) Validation of RNA-Seq data by RT-qPCR using representative genes from each Group was performed using RT-qPCR and the Pearson $r$ correlation coefficient was calculated from the geometric mean values. (RNA-Seq - three replicates, RT-qPCR - six replicates, geometric mean with geometric standard deviation). DEGs - differentially expressed genes, pw - post wounding

A total of 2128 genes $(9.0 \%)$ were identified as differentially expressed genes (DEGs) during 90 min of embryonic wound healing. 6\% of these DEGs (134 genes) (example: lep, fosl1, aqp3) were found to be specific for healing (absent in uninjured tissue but expressed during healing). DEGs were clustered into four groups based on their temporal expression profiles (Fig. 3b-i). Number of genes for Gene Ontology (GO) analysis was reduced to include only well annotated genes with a known human homolog. Several interesting genes for each group are 
presented based on their importance for the regulation of healing and development as derived from published literature. Downregulated genes during wound healing were clustered in Group 1 (Fig. 3b). This group contained 187 genes (111 for GO analysis) such as $d h h$, gata6 and bmpr2, which are mainly responsible for processes involved in the regulation of developmental control (Fig. 3c, Additional file 2: Figure S1A). Members of Group 2 showed a continuous increase of gene expression during the first $90 \mathrm{~min}$ of healing (Fig. 3d). This group comprised of 870 genes (600 for GO analysis), with their GO terms indicating that they are responsible for regulation of cell proliferation, cell death and response to chemical stimuli (Fig. 3e, Additional file 2: Figure S1B). The Group 3 consisted of 177 genes (96 for GO analysis), whose expression started $30 \mathrm{~min}$ pw (Fig. 3f). These genes are associated with cytokinemediated signalling pathways and with the defence/immune response (Fig. 3g, Additional file 2: Figure S1C). The Group 4 represents 166 genes (120 for GO analysis) that were expressed strongly between 30 and $60 \mathrm{~min}$ with minimal expression before and after this period (Fig. 3h). Interestingly, most of the genes from the Group 4 regulate transcription, with many of them being associated with the AP-1 transcription pathway (Fig. 3i, Additional file 2: Figure S1D). The remaining 728 DEGs clustered into two additional groups (Additional file 1: File S1). However, they were excluded from further analysis due to the low reproducibility (high variability between experiments) and low expression changes (absolute value of $\log 2$ FoldChange $<1$ for comparison between $0 \mathrm{~min}$ pw and any time point for most of the genes) which suggested their potentially minimal effect during healing.

Using independent experimental setups, the temporal profile for one gene from each major cluster group was analysed using RT-qPCR. The profile results correlated well with those obtained from the RNA-Seq (Fig. 3j).

\section{NO is important for the regulation of gene expression during embryonic wound healing}

RNA-Seq comparison between control and NO inhibited embryos (mixture of nos $1+$ nos3-MO and chemical inhibitor TRIM) was performed using the same experimental workflow as above (Fig. 4a, Additional file 3: File S2). A total of 269 genes showed contrasting expression profiles. Clustering based on expression profiles across the two conditions, divided genes into three groups labelled with an apostrophe (') (Fig. 4b-g).

Group 1' consisted of 102 genes (86 for GO analysis), whose expression was increased in control embryos, but their expression was stable/absent after NO inhibition (Fig. 4b). Based on the GO analysis, these genes are mainly responsible for the regulation of immune system response
(Fig. 4c, Additional file 4: Figure S2A). Thirty-one genes (25 for GO analysis) clustered in Group 2' and their expression was similar until $60 \mathrm{~min}$ pw between control and inhibited samples. After that their expression was quickly decreased in control embryos, but continued to increase in the inhibited embryos (Fig. 4d). This group comprised of GO terms related to transcription regulation important for cell proliferation, differentiation and death (Fig. 4e, Additional file 4: Figure S2B). Group 3' contained 136 genes (111 for GO analysis), whose expression was downregulated in the control embryos, but was not changed after NO inhibition (Fig. 4f). GO analysis identified mainly regulation of developmental and metabolic processes (Fig. 4g, Additional file 4: Figure S2C).

Two interesting genes from Group 1' and Group 2', lep and fos respectively, which had minimal expression within the uninjured tissue but fast activation following injury, and also a strong dependence on $\mathrm{NO}$ production were selected for detailed analysis. The results from RNA-Seq (Fig. 4h, j) were verified in detail using RTqPCR (Fig. 4i, k) and in situ hybridization (Fig. 4l, m) using independent experimental samples. Expression of fos was dramatically increased after injury in control embryos with peak at $30 \mathrm{~min}$ pw. In contrast, NO inhibited embryos showed a stable or a slightly increased fos level between 30 to $90 \mathrm{~min}$. In situ hybridization of fos showed minimal signal at $60 \mathrm{~min}$ pw in control embryos, but a strong enrichment in both TRIM and MOs inhibited embryos at that time (Fig. 4l, m). The lep gene was undetectable even by RT-qPCR in uninjured embryos and it was not expressed during $30 \mathrm{~min}$ pw. Its expression appeared at $60 \mathrm{~min}$ pw and continuously increased. NO inhibition led to significant reduction of lep expression (Fig. 4i, k).

\section{Changes of tissue morphology at the wound edge after NO inhibition}

Immunohistochemistry using morphology markers such as actin (cell shape), $\beta$-catenin (cell shape) and laminin (basement membrane) was performed to reveal morphological changes at the wound edges of control and $\mathrm{NO}$ inhibited embryos (Fig. 5). Laminin staining experiments were performed at 180 and $360 \mathrm{~min}$ pw. Control embryos showed discontinuous laminin staining in the wound site $180 \mathrm{~min}$ after injury and complete restoration at $360 \mathrm{~min}$ pw. Acute inhibition of NO production using TRIM showed minimal laminin production in wound site at 180 and $360 \mathrm{~min}$ pw. As expected, acute inhibition had no effect on the laminin layer in the tissue behind the wound edge. Interestingly, usage of nos $1+$ nos3-MO led to different effects than inhibition using TRIM. In general, the laminin layer was weaker in treated embryos in comparison with the controls even in uninjured tissue and there were no signs of the 

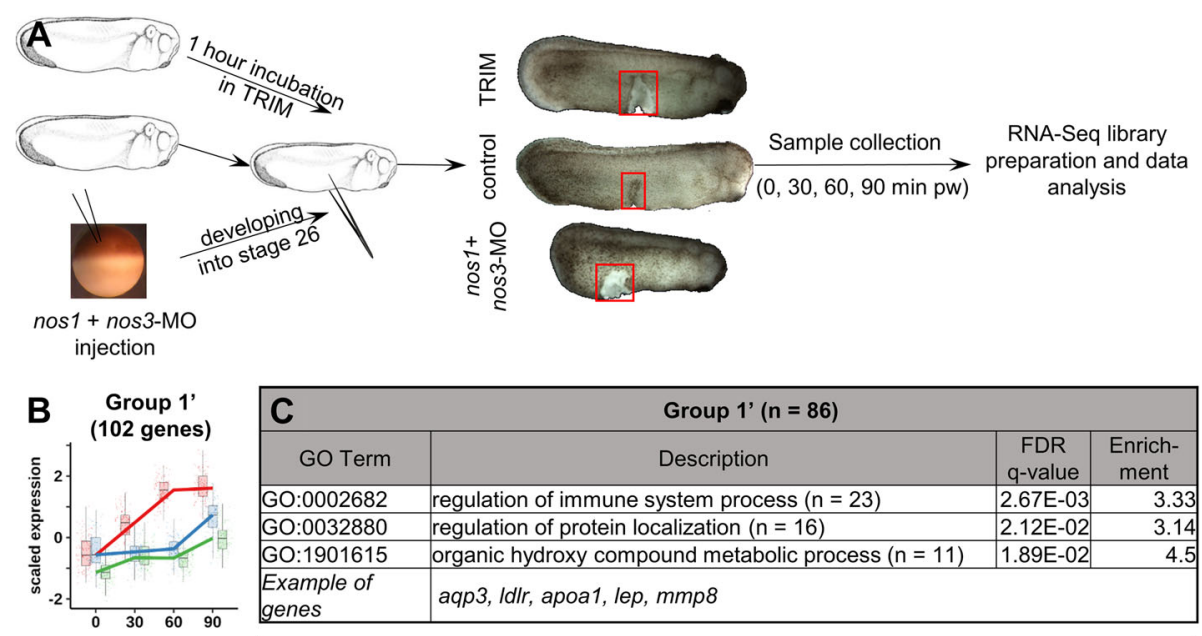

\begin{tabular}{|l|l|r|r|}
\hline \multicolumn{4}{|c|}{ Group 1' $(\mathbf{n = 8 6 )}$} \\
\hline \multicolumn{1}{|c|}{ GO Term } & \multicolumn{1}{|c|}{ Description } & $\begin{array}{c}\text { FDR } \\
\text { q-value }\end{array}$ & $\begin{array}{c}\text { Enrich- } \\
\text { ment }\end{array}$ \\
\hline GO:0002682 & regulation of immune system process $(n=23)$ & $2.67 \mathrm{E}-03$ & 3.33 \\
\hline GO:0032880 & regulation of protein localization $(n=16)$ & $2.12 \mathrm{E}-02$ & 3.14 \\
\hline GO:1901615 & organic hydroxy compound metabolic process $(n=11)$ & $1.89 \mathrm{E}-02$ & 4.5 \\
\hline $\begin{array}{l}\text { Example of } \\
\text { genes }\end{array}$ & aqp3, Idlr, apoa1, lep, mmp8 & \\
\hline
\end{tabular}

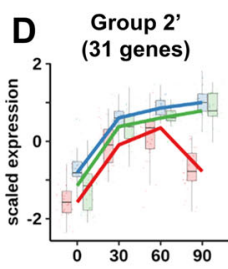

\begin{tabular}{|l|l|r|r|}
\hline E & \multicolumn{3}{|c|}{ Group 2' $(n=25)$} \\
\hline GO:0031326 & regulation of cellular biosynthetic process $(n=20)$ & $4.52 E-05$ & 3.45 \\
\hline GO:0010941 & regulation of cell death $(n=14)$ & $5.12 \mathrm{E}-05$ & 5.52 \\
\hline GO:0042127 & regulation of cell proliferation $(n=12)$ & $4.67 \mathrm{E}-04$ & 4.93 \\
\hline $\begin{array}{l}\text { Example of } \\
\text { genes }\end{array}$ & jun, fos, atf3, socs3 & & \\
\hline
\end{tabular}

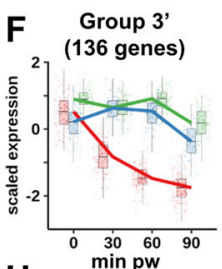

\begin{tabular}{|l|l|r|r|}
\hline G & \multicolumn{3}{|c|}{ Group 3' $(\mathbf{n}=111)$} \\
\hline GO:0051252 & regulation of RNA metabolic process $(n=46)$ & $5.70 E-03$ & 2.02 \\
\hline GO:0050793 & regulation of developmental process $(n=36)$ & $2.03 \mathrm{E}-02$ & \\
\hline $\begin{array}{l}\text { Example of } \\
\text { genes }\end{array}$ & $n p r 2$, tiam1, Irp4, rbfox2, tnfrsf19 & \\
\hline
\end{tabular}

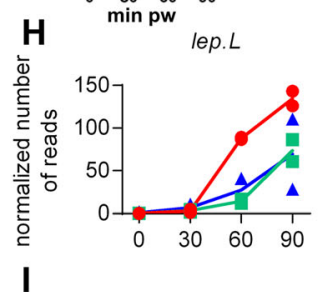

lep
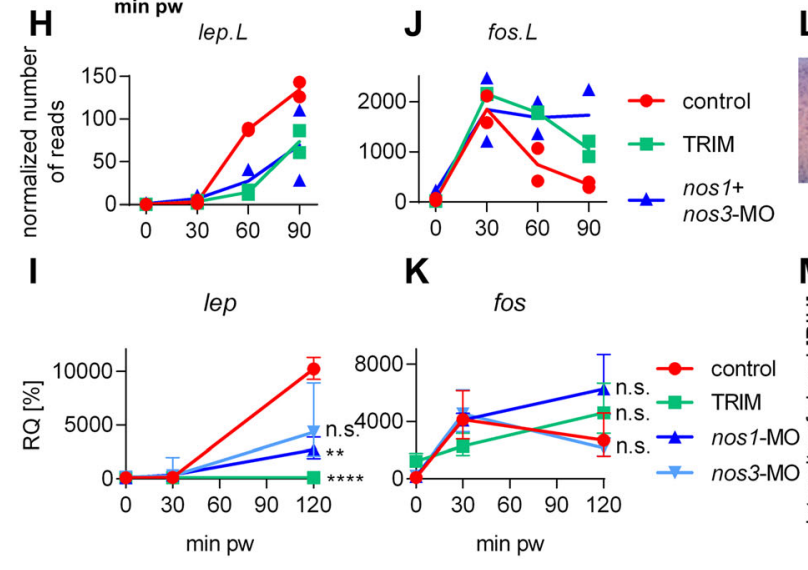

$\mathbf{L}$

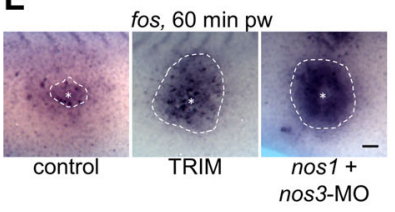

M

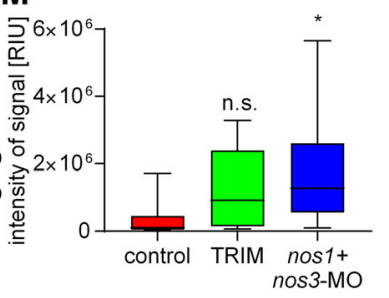

Fig. 4 Changes in gene expression during wound healing after inhibition of NO production. (a) Graphical description of RNA-Seq experiment comparing control and NO inhibited embryonic wound healing. Only the part marked by red rectangle was collected and used for RNA isolation and sequencing. (b-g) DEGs, which were identified in RNA-Seq, were grouped based on their expression profile relatively to 0 minutes and GO analysis was performed. (b, $\mathbf{d}, \mathbf{f}$ ) Expression profiles of genes are representative of the $z$-score of the regularized log transformation of the normalized counts. $(\mathbf{c}, \mathbf{e}, \mathbf{g})$ Genes with annotation and human homolog were used for GO analysis. Numbers of analysed genes are in the table together with the representative GO terms for each group. (h) RNA-Seq result of lep expression was verified (i) using RT-qPCR, separately for nos 1$\mathrm{MO}$ and nos3-MO. (j) Similarly, RNA-Seq result of fos expression was verified using (k) RT-qPCR (data are normalized to 0 minutes pw in controls, three replicates, geometric mean with geometric standard deviation, two-sided t-test from log2 values of relative expression between inhibited samples and control in 120 minutes pw), and (I) in situ hybridization. Site of injury is marked with a star and the signal where fos is expressed is circled by dot line $(S c a l e ~ b a r=100 \mu \mathrm{m})(\mathrm{M})$ Intensity of blue signal around site of injury were measured (one-way Anova, Dunnett's multiple comparisons test, minimum 8 replicates). ${ }^{* * *}-p<.0001,{ }^{* *}-p<.01,{ }^{*}-p<.05$, n.s. $-p>.05$ DEGs - differentially expressed genes, pw - post wounding, RIU - relative intensity unit 


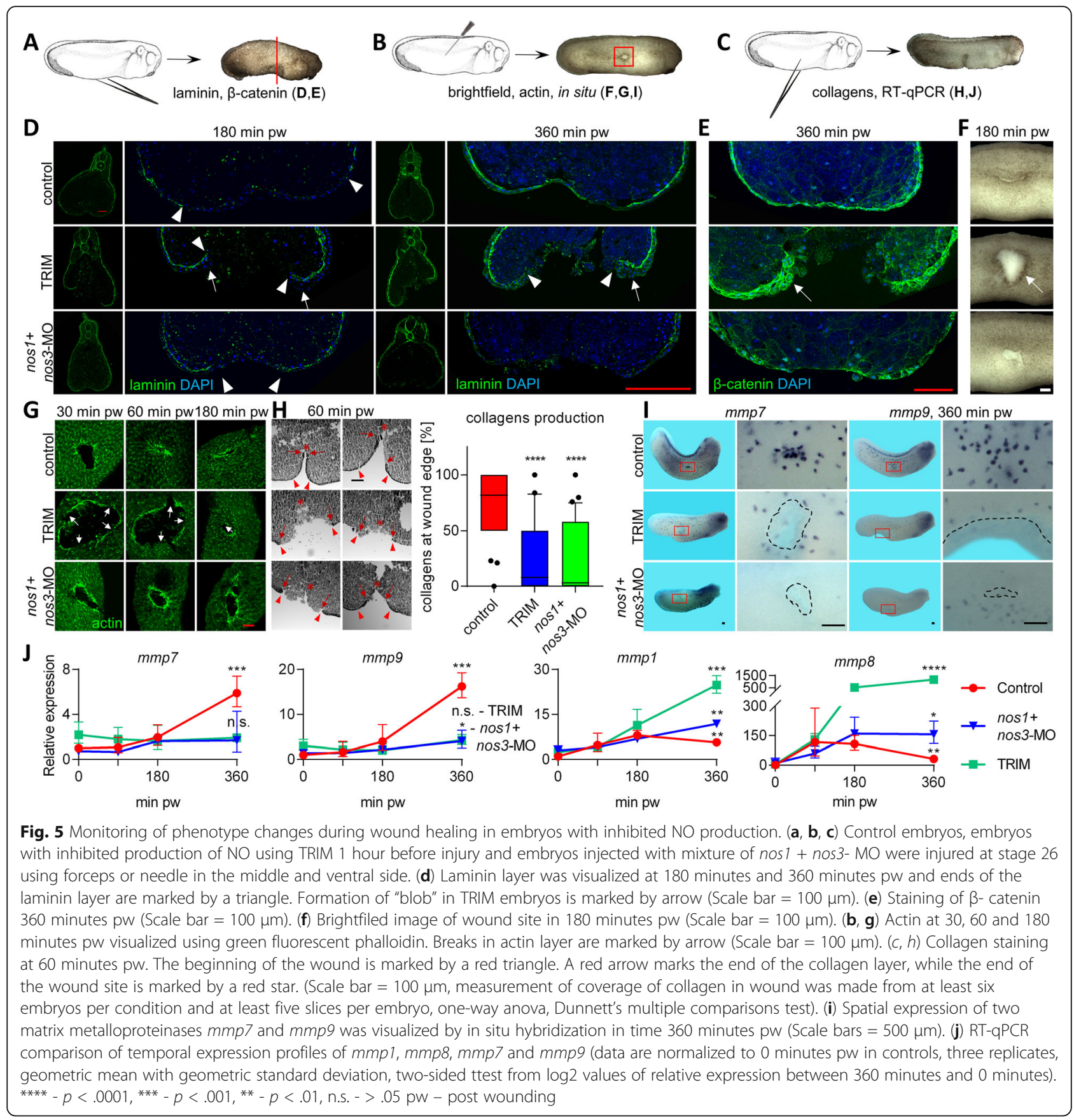

basement membrane reformation at $360 \mathrm{~min} \mathrm{pw} \mathrm{(Fig.} \mathrm{5d).}$ $\beta$-catenin staining revealed changes in cell migration in NO inhibited embryos resulting in accumulation on the wound edge. Especially in TRIM treated embryos, cells responsible for wound closure formed clumps of cell aggregates or "cell blobs" at the wound edges, potentially preventing wound closure (Fig. 5e). These accumulated cells were observed as a dark edge around the wound, which was observable also in the brightfield images of healing embryos (Fig. 5f).
A well-described process during embryonic wound healing is the formation of an actinomyosin ring around the wound and it was studied using phalloidin for staining of actin (Fig. 5g). Acute NO inhibition by TRIM treatment led to decreased formation of actin ring around the wound edge with many breaks within the actin layer. In addition, the cell morphology at the wound edge of TRIM treated embryos was also abnormal (Additional file 5: Figure S3A). Chronic NO inhibition using MOs resulted in a different phenotype. Actin 
was produced at a higher level around the wound edge and formed a complex structure inside of the injured MO embryos (Additional file 5: Figure S3B).

Collagen synthesis and its correct deposition is also an important step during wound healing. Previous research have already shown that $\mathrm{NO}$ is required for collagen synthesis [53, 54]. Masson's trichrome staining was performed to compare collagen production between control and NO inhibited embryos. Collagen layer around wound edge was studied at $60 \mathrm{~min}$ pw. Collagen covered $82 \%$ of wound surface in control embryos compared to only $8 \%$ in TRIM treated embryos and $3 \%$ in NO inhibited embryos (Fig. 5h, i).

Defects of basement membrane formation and collagen synthesis as showed in Fig. 5d and h respectively, are tightly connected with the production of matrix metalloproteinases (MMPs) enzymes that are responsible for tissue remodelling. The spatial and temporal expression analyses of four ( $m m p 1, m m p 7, m m p 8, m m p 9$ ) of the most interesting MMPs (based on our RNA-Seq data) were performed during middle and late phases of wound healing (Fig. 5i, j). The genes $m m p 7$ and $m m p 9$ are also markers for migrating myeloid progenitors. Additionally, $m m p 1$ and $m m p 8$ are known regulators of cell migration during wound healing. Migration of cells expressing $m m p 7$ and $m m p 9$ to the wound site were observed at 360 min pw in control embryos. Inhibition of NO production led to a reduction in the number of these cells and also a retardation of their migration (Fig. 5i). RT-qPCR expression profiles revealed an approximately 6 -fold and 16 -fold increase of $m m p 7$ and $m m p 9$ respectively at $360 \mathrm{~min}$ pw in control embryos compared to no gene expression changes in NO inhibited embryos (Fig. 5j). RT-qPCR analysis of $m m p 1$ and $m m p 8$ showed an opposite result. The mmp 1 and $m m p 8$ expressions increased during $90 \mathrm{~min} \mathrm{pw}$ in both the control and treated embryos. However, gene expression at later time points showed a difference between the control and NO inhibited embryos. Whereas $m m p 1$ and $m m p 8$ expression started to decrease after 90 min, their levels in NO inhibited embryos continued to increase (Fig. 5j).

\section{Leptin is a downstream target of NO signalling during the healing}

Leptin is known as an activator of NO release [55], but RNA-Seq and RT-qPCR comparison between control and NO inhibited embryos revealed lep to be downregulated in NO inhibited wound healing (Fig. 6a, Fig. 4h). Importance of lep for wound healing was analysed. Usage of lep-MO led to a decrease in the speed of wound closure (Fig. 6b, c). Expression of socs3 is usually measured to monitor the activity of Lep. We confirmed, that usage of lep-MO led to no changes of expression of socs3 during wound healing (Fig. 6d). Control embryos showed an increased expression of socs 3 during the first $30 \mathrm{~min}$ pw followed by a decreased expression during the middle phase. However, inhibition of NO production using MOs led to increasing expression of socs 3 during the studied 90 min of embryonic wound healing. Expression of fos was similar between both lep-MO and nos $1+$ nos3-MO (Fig. 6e). To verify the impact of lep for wound healing process, the immunohistochemistry analysis of actin and laminin was performed. Comparison of actin formation at the wound edge showed that lep loss-offunction led to extreme formation of actin during first $60 \mathrm{~min}$ pw (Fig. 6f) and showed minimal laminin production in wound site at $180 \mathrm{~min}$ pw (Fig. 6g).

\section{Discussion}

Embryonic wound healing, which results in a scar-less wound closure, is a fascinating biological phenomenon. However, very little is still known about the molecular mechanism that regulate this process. In this research, we utilized the popular model Xenopus laevis embryos to reveal the different healing phases and their important genes [10, 28, 56, 57]. Embryonic healing is composed of the early phase which lasts less than $30 \mathrm{~min}$ and results in the near completion of wound closure. The following middle phase takes place between 30 and $90 \mathrm{~min}$ and ends with the wound site completely closed by filopodia/ lamellipodia activity [10]. In our study, we described an additional late healing phase during which the tissue under the wound site is remodelled and could take several hours to complete (Fig. 7).

The important difference between embryonic and adult wound healing is the presence and activity of the immune/inflammation system. Inflammation response has been suggested many times as the key component that results in scaring during adult wound healing [58, 59]. However, recent studies also claim that inflammation is required for embryonic healing and that the mechanism is more complicated [60]. Inflammation is usually characterized by an abnormal production of small radical molecules, which serve as an antimicrobial agent around the wound. ROS are among the most studied molecules during embryonic and adult wound healing $[20,61,62]$. However, the wound healing can also be regulated by other small gas molecules (also called gasotransmitters) such as carbon monoxide (CO) [63, 64], hydrogen sulphide $\left(\mathrm{H}_{2} \mathrm{~S}\right)[65,66]$ and NO. Surprisingly, in recent studies, NO received very little attention compared to the ROS. NO is usually connected with angiogenesis and inflammation [67] during adult wound healing [68-70] or with extracellular matrix modifications [38]. In our study, we analysed the role of NO during wound healing at the developmental stage 26 . This is an ideal stage for the analysing of embryonic wound healing as it represents the embryonic transitional period 


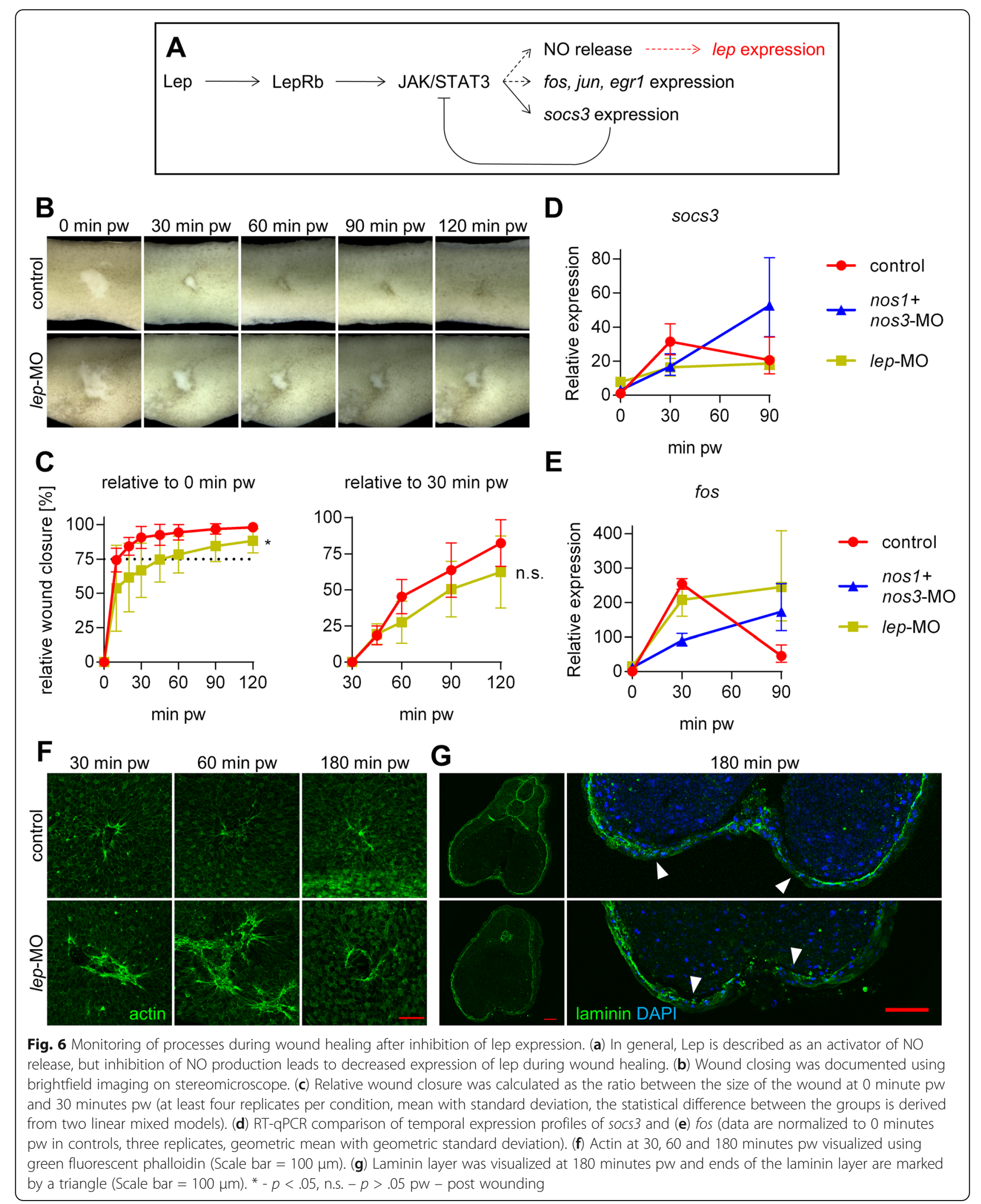




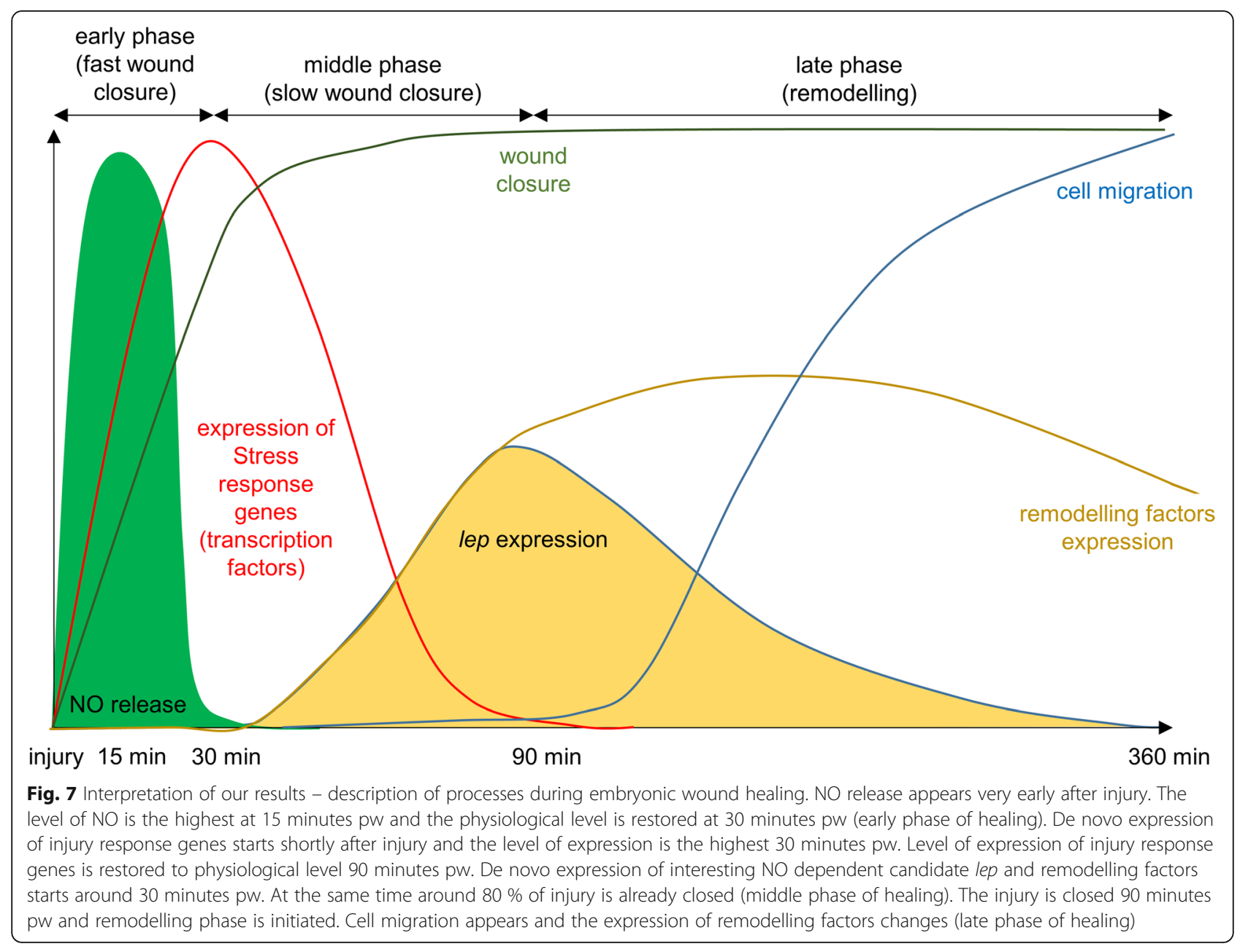

between partially differentiated cells of the gastrula stage and the later complex tissues, including blood and immune cells that are already formed during later stages.

\section{The early phase of healing (0-30 min after injury)}

The first NO production connected with healing was detected shortly after injury and its level peaked at $15 \mathrm{~min}$ (Fig. 1c-e). The level of NO was abnormally high compared to the physiological level and we estimate that there was an increase of more than three folds. The results indicate that a high level of NO acts mainly in a cGMPindependent way during the early phase (Additional file 6 : Figure S4). Moreover, the importance of NO production is also reflected in its conserved increasing rate of production after injury of the very early stages such as stage 10 (gastrula), stage 20 (neurula) (Fig. 1g) and also during the late developmental stages such as stage 41 and later (Fig. 1e). High levels of NO production has potentially several other effects such as a nonspecific inflammatory response with antimicrobial activity or regulation of chemotaxis [71]. NO production then decreases after 15 min and returns to physiological state around $30 \mathrm{~min}$.
Interestingly at the same time, ROS production starts and continues [20,72]. Wound healing is initiated with the rapid calcium release in the cells at the wound edge and the calcium wave spreads radially within seconds. The released calcium ions triggers the production of the actinomyosin ring that is responsible for the quick wound constriction [12]. The level of calcium returns to normal within a few minutes [73, 74]. The time sequence of calcium, NO and ROS production suggests a connection among these small molecules [12, 20, 72-74], but more thorough study are required to prove this hypothesis.

Interestingly, the same principle of calcium release followed by ROS has been observed in Xenopus laevis eggs after fertilization [75]. However, we have not seen NO production in stage 1 (egg) or at stage 5 (blastula) (Fig. 1g), following an injury to the embryo. We believe that NO may also be produced at these early stages, but the methods used to currently assess $\mathrm{NO}$ are limited in resolution and cannot detect its rapid and/or low concentration of release.

Temporal RNA-Seq analysis revealed that the expression of only a few genes were significantly changing 
(9\% of 23,609 expressed genes) during the first $90 \mathrm{~min}$ after injury, with only 166 of them showing a maximum expression at $30 \mathrm{~min}$ after injury (Fig. 3h). Moreover, we identified the same set of genes also in the healing tissue after tail amputation at developmental stage 41 (Additional file 7: Figure S5). Interestingly, the list of genes overlapped nicely with the results obtained from another study [18]. The goal of the Ding et al. [18] study was to reveal dorsal and ventral specific transcriptomes at the gastrula stage, but because of long dissection time and parallel healing the authors revealed group of early injury response genes such as jun, fos, egr 1 and junb. Interestingly, expression of early response genes was also found in adult tissues $60 \mathrm{~min}$ post mortem [76], and as an artefact during dissociation of tissue $[77,78]$. Based on the literature and our results, we speculate that these genes are generally important for cells dealing with stress conditions and therefore we propose that these genes should be referred to as "Stress response genes".

\section{The middle phase of embryonic healing (30-90 min after injury)}

During the early phase, the wound area is reduced to roughly $20 \%$ within the first $30 \mathrm{~min}$ after injury. In the middle phase, NO returns to the normal physiological level, where it has a potentially positive effect on the cells around the wound. RNA-Seq analysis identified a group of genes, whose expression started to increase 30 min after injury. These genes are responsible for cytokine production or defence response. Several genes such as lep and $i g f b p 2$ were shown previously to be important for healing and/or regeneration [79-81] and are connected with cell metabolism. Leptin is a small $16 \mathrm{kDa}$ peptide hormone, which acts via transmembrane receptors (Lep-R, also known as OB-R) and regulates an energy homeostasis [82]. Relations between NO and Lep have been previously studied. However, there is still no consensus on their interactions, as some of these studies have observed NO production by Lep stimulation, through PKA and MAPK activation [83], while others have shown an exact opposite effect - attenuation of NO production after Lep exposition [84, 85].

Comparison of the temporal expression profile of the control with those from NO inhibited embryos revealed three groups of affected genes (Fig. 4). The first group (Group 1') contains genes such as lep, $m m p 8$ and igfbp2 (mentioned above). The expression of these genes gradually increased during normal healing but was completely inhibited or delayed in NO inhibited embryos (Fig. 4b, Fig. 5j). This suggests the importance of $\mathrm{NO}$ as a gene expression regulator for cell metabolism and tissue remodelling. Our results showed that the lep gene serves as a downstream target of NO (Fig. 4h, i), which to our knowledge is the first time this has been observed. We performed lep loss-of-function experiments and results during wound healing were nearly identical with NO inhibition (Fig. 6e). Interestingly, the effect of lep-MO was extremely dependent on its concentration. Injection of a few nanograms below or above optimal concentration led to no phenotype or an inhibition of development at the neurula stage, which later led to death and cellular decay. We tested several options for combined NO - lep phenotype rescue using either NO donors or Lep protein/mRNA, but none of our experiments showed a significant improvement in healing capacity. We speculate, that the lack of an effect may be due to the requirement for a defined particular concentration of Lep to circumvent the effect of the given lepMO concentration range.

The second group (Group 2') is formed from Stress response genes. Embryos at stage 26 with inhibited NO production showed an increase in the expression of some of these genes in the whole embryos (e.g. fos, jun), more than 1.5-fold [86]. Dissected healing tissue showed at the beginning the same increase of gene expression at 30 min after injury as in control embryos. However, expression of these genes were turned off during the middle phase of healing in controls in contrast to the continuous growth of expression in NO inhibited embryos. We speculate that persistent cell stress response reflected by continuous expression of Stress response genes have an impact on wound closure and especially on the remodelling phase of wounded tissue. NO signal could be considered as back-signalling switch of cellular stress. The third group (Group 3') consists of genes, which are downregulated in normal healing, but their level remains constant after $\mathrm{NO}$ inhibition. Unfortunately, biological interpretation of the roles of these genes during wound healing is much more complex and require further studies.

Subsequently, we wanted to elucidate the mechanism of NO on gene expression regulation during the middle phase of wound healing. NO has been shown to regulate gene expression through the cGMP-dependent pathway in many biological situations such as apoptosis [87], proliferation [88] and angiogenesis [89]. Based on our results, we concluded that this pathway is important during the middle phase of embryonic wound healing. We observed similar wound healing defects in embryos with chemically induced sGC inhibition or with prkg1 loss-of-function phenotype. In addition, gene expression changes of selected candidates (lep and fos) showed identical profiles as embryos with inhibited NO production.

Morphological analyses using immunohistochemistry and collagen labelling revealed two different phenotypes in wound tissues. Control tissue showed proper cell sheet organization, basement membrane remodelling at 
the wound edges and complete restoration of laminin layer at the late phase. Chronical NO production inhibition caused abnormal basement membrane formation in embryos injected with MOs at the one cell stage. Even though the early phase of healing looks similar to control embryos, the middle and late phases revealed basement membrane formation defects, which resulted in delayed or missing wound closure. In the NO inhibited embryo, we speculate that the cells at the wound edge cannot move along the disrupted basement membrane, which is crucial for the fusion of the wound edge. Acute NO production inhibition achieved by TRIM inhibitor showed a different cellular behaviours at the wound edge. Cells at the wound edge formed "cell blobs" preventing cell movement during healing, which resulted in defects even during the early phase of healing. Laminin layer at the wound edge is intact, which supports cell movement defect. Replacement of collagen layer in the epidermis during middle phases of healing was found to be significantly reduced in NO inhibited embryos, which support previously discovered connection between $\mathrm{NO}$ and collagen synthesis [90].

An interesting phenomenon of adult wound healing is the migration and activity of immune cells. NO production is required for defence response/naïve immune activity during the early and middle phase of healing. Since embryos do not have a fully functional immune system, which would include a fully differentiated B and $\mathrm{T}$ cells that only develop at around 12 days post fertilization (stage 47) in Xenopus laevis [91], we hypothesize that NO acts differently in our experiments. Instead, during early development, primitive myeloid cells may provide a positive effect on defence and tissue remodelling. However, expression levels of gene markers of this cell type such as $m m p 7, m m p 9$, spib and mpo are not changed in NO inhibited embryos during the early and middle phases of embryonic healing. Surprisingly, their expression is changed after wound closure (more than $2 \mathrm{~h}$ after injury, Fig. 5i, j) and it suggests that there is a following late phase of wound healing which has not been sufficiently discussed in the available literature.

\section{The late phase of embryonic wound healing (more than $90 \mathrm{~min}$ )}

The late phase of embryonic wound healing has not been defined yet. It starts after wound closure. The tissue beneath the wound site is remodelled and cells such as primitive myeloid cells migrate into the wounded place (Fig. 5). Two matrix metalloproteinases (gelatinases), $m m p 7$ and $m m p 9$ are used as markers for primitive myeloid cells [92-95]. Embryos with inhibited NO production showed a reduction of primitive myeloid cell migration to the wound site and suggests a reduction of Mmp7 and
Mmp9 activity in remodelled wound tissue. In addition, RNA-Seq expression profiles of other mmps [96], which are important for tissue remodelling such as collagenases $m m p 1$ and $m m p 8$, were changed at the late phase of healing in contrast to constant expression during early and middle phases. Expression of $m m p 1$ was previously shown to be regulated by laminin expression [97] and abnormal laminin production in NO inhibited embryos led to overexpression and potentially to detrimental over-activity of MMP1 enzyme in the wound tissue. Overexpression of $m m p 8$ was shown to cause chronic wounds [98], which is similar to its expression during the late phase of healing of NO inhibited embryos. All results together show not only existence of remodelling phase of embryonic wound healing but regulation of late phase by NO signalling during the early phase too.

\section{The relevance of NO healing properties}

In this work, we described the role of NO during embryonic wound healing. We showed that $\mathrm{NO}$ is crucial for the early and middle healing phases and its activity depends on the quantity of its production. NO is not only required for proper wound healing. The other positive effect of NO during wound healing can also be achieved therapeutically through its supplementation with additional NO (for example using NO donors), which can significantly improve healing, especially in chronically non-healing tissues.

NO donor use has been found to improve wound healing in diabetic rats [99] and NOD-SCID (diabetic immunodeficient) mice [100]. Moreover, it was observed for in vitro wound healing assays that $\mathrm{NO}$ donors can speed up cell migration and collagen deposition [101, 102]. Application of sildenafil cream (inhibitor of cGMP specific phosphodiesterase type 5 - PDE5) on human epidermal injuries has been found to result in faster wound healing [103]. We were not able to reproduce a significant faster healing in embryos through the use of the NO donor, S-Nitroso-N-acetylpenicillamine (SNAP). We believe it is a matter of just finding the correct NO concentration and also the appropriate means of administration. However, owing to the fast rate of embryonic wound healing, it will be difficult to accurately measure the time difference for any increase in healing when using $\mathrm{NO}$ donors.

Perhaps the most attractive usage of NO donors is for human medicine. The relevance of NO donors for different human therapies was recently reviewed by Yang, et al. [104]. NO donors were applied, for example, during pressure ulcer treatment and the results showed statistically significant improvement of the speed of wound healing [105]. This makes NO donor an ideal potential treatment for patients with diabetic foot ulcers [106]. However, the current suggested mechanism of $\mathrm{NO}$ activity during 
wound healing has been only limited to mainly angiogenesis and inflammation. In this study, we also suggested here a new connection between upstream NO and downstream Lep. This could be relevant for understanding the molecular regulations during many chronical diseases such as high-blood pressure, diabetes and obesity in context with chronic wound healing problems. It appears that NO has more functions during healing, and therefore additional studies will be required if it is to be used in the future for routine targeted/personalized treatment.

\section{Conclusions}

The main goal of this study was to identify the processes that are regulated by NO during the healing of embryos that lack a developed vascular and immune system. Our results showed that inhibition of NO led to later developmental defects and that $\mathrm{NO}$ is also essential for the regulation of other processes/systems other that the ones mentioned above. We observed that the production of NO during the early phase is crucial for the regulation of gene expression during the middle phase of healing. $\mathrm{NO}$ was also found to regulate the de novo expression of genes related to metabolism (such as lep and igfbp2). Additionally, inhibition of NO led to permanent stress of the cells around the wound edge, which is described by an increased expression of "Stress response genes" during the healing of the NO inhibited embryos. Additionally, we observed and characterized a new phase of healing, the late healing phase, which continues for hours after wound closure. The results provides new insight into the regulation of scarless embryonic healing.

\section{Methods}

\section{Ethics statement}

All animal experiments were performed in accordance with protocols approved by the animal committee of the Czech Academy of Sciences and were performed according to EU legislation (including animal handling guidelines and regulations).

\section{Embryo preparation}

Xenopus laevis adults were obtained from the European Xenopus Resource Centre (EXRC) and grown in our breeding facility. Xenopus laevis embryos were obtained by in vitro fertilization [107]. Females were stimulated with $500 \mathrm{U}$ of human chorionic gonadotropin (Sigma-Aldrich, CG10) and eggs were collected the following day. Eggs were in vitro fertilized using testes suspension and the jelly coats were removed by $2 \%$ cysteine treatment. After fertilization, the embryos were incubated in $0.1 \mathrm{x}$ MBS until gastrulation where they were incubated in $0.1 \mathrm{x}$ MBS medium with the addition of gentamicin $(20 \mu \mathrm{g} / \mathrm{mL}$, Sigma-Aldrich G1397). Embryos were incubated at $15^{\circ} \mathrm{C}$. Developmental stages were scored according to Nieuwkoop \& Faber [108].

\section{NO staining}

The middle region of five embryos were injured using a needle (outside diameter $0.45 \mathrm{~mm}$, Gauge $26 \times 1$ "). NO was stained with 5,6-Diaminofluorescein diacetate (DAF-2DA - Cayman 85,165). The stain was prepared as a $5 \mathrm{mM}$ stock solution in DMSO, which was then diluted 1:150 in cultivation media. Embryos were transferred into media with DAF-2DA solution 15 min prior imaging. After that, embryos were fixed in $4 \%$ paraformaldehyde in phosphate buffer (PFA) and incubated for $30 \mathrm{~min}$ at the room temperature (e.g. time 0 , embryos were transferred into DAF-2DA containing solution, cultivated for $15 \mathrm{~min}$, and fixed immediately after injury). After fixation, embryos were washed two times for 5 min with phosphate buffer solution (PBS) with $1 \%$ Tween-100 buffer (PBT) and imaged using Leica MZ FLIII fluorescent stereoscope equipped with a Nikon digital sight DS-Fi2 camera. Fluorescent intensities around the wound site were analysed using FiJI $(\mathrm{NIH}$, v1.52n) with Corrected Total Fluorescence (CTF) calculated using formula:

$$
\begin{aligned}
\mathrm{CTF} & =\text { Integrated Denisty } \\
& -(\text { Area around the wound } * \text { Mean fluorescence of background })
\end{aligned}
$$

The statistical significance was calculated relative to time 0 min using GraphPad Prism 7 and One-way ANOVA with Dunnett's multiple comparisons test.

Similarly, three tadpoles at stage 41 were anaesthetized for 5 min using 0.025\% MS222 (Tricaine, Sigma-Aldrich, E10521) diluted in 0.1x MMR medium and about $50 \%$ of the tail length from the tip was amputated using a scalpel. Tadpoles were then transferred to 0.1x MMR with gentamicin $(50 \mu \mathrm{g} / \mathrm{ml})$ containing $\mathrm{NO}$ staining solution. The site of amputation of tails was imaged at 15, 30, 60, 180 min post amputation.

\section{Morpholino injection}

All morpholino oligonucleotides (MOs) were purchased from Gene Tools, LLC (Phliomath, OR, USA) and diluted to a final concentration of $17 \mathrm{ng} / \mu \mathrm{l}$. The amount of injected MO was: $2 \mathrm{nl}$ of standard control MO (5'-CCTCTTACCT CAGTTACAATTTATA-3' designed by Gene Tools), $2 \mathrm{nl}$ of nos3-MO (5'-AAAAGCCAAGCACTACTCACCGTTT$3^{\prime}$ [86]), $1 \mathrm{nl}$ of nos1-MO (5' ${ }^{\prime}$-TGGCTAAAAGAACACAGG ACATCAA-3' [109]), $2 \mathrm{nl}$ of prkg1-MO (5'-TTCAGC TTCAATGCTCATACCTGCC-3' [86]), $0.3 \mathrm{nl}$ of lep-MO (5'-TTGCAGTGTCCATGTTTCTCACCTG-3') and $3 \mathrm{nl}$ of mixture nos $1+$ nos3-MO in 1:2 ratio. Injections were performed at the one-cell stage embryos for all cases. The effectivity of nos1-MO and nos3-MO were tested in previous 
studies $[86,109]$. The specificity of prkg1-MO and lep-MO were tested using PCR (Additional file 12: Figure S8).

\section{Chemical inhibition of NO production and SGC activity}

Chemical inhibitors were selected to block NO production and sGC activation.

1-(2-Trifluoromethylphenyl) imidazole (TRIM, SigmaAldrich, T7313) is a reversible inhibitor that preferentially blocks NOS2 and NOS1 activity and also partially blocks NOS3 activity. TRIM was prepared as a $1 \mathrm{M}$ stock solution in dimethyl sulfoxide (DMSO) and its final concentration in media was $2 \mathrm{mM}$. $1 \mathrm{H}-[1,2,4]$ Oxadiazolo [4,3a]quinoxalin-1-one (ODQ, Sigma-Aldrich, O3636) is an irreversible and competitive inhibitor of soluble guanylate cyclase (sGC). ODQ was prepared as $100 \mathrm{mM}$ stock solution in DMSO and used at a final concentration of $0.2 \mathrm{mM}$.

The vitelline membranes were manually removed from embryos at stage 24 using forceps (FST, 11203-23). Embryos were incubated in $0.1 \mathrm{x}$ MBS media with added inhibitors $1 \mathrm{~h}$ prior to wounding and during the whole time of monitoring of healing. Media were changed immediately after wounding and again at 30,90 and 180 min pw to avoid inhibition of wound healing caused by decaying material. The effectivity of TRIM to inhibit the production of $\mathrm{NO}$ was tested by staining for $\mathrm{NO}$ using DAF-2DA (Additional file 13: Figure S9).

\section{Wound healing monitoring}

Wounds were created using a needle (outside diameter $0.45 \mathrm{~mm}$, Gauge $\left.26 \times 1^{\prime \prime}\right)$ puncture to obtain constant damage size in the in the middle of the lateral side of the embryo. Embryos at stage 26 were injured and wound closing was documented using brightfield imaging on stereomicroscope (Nikon SMZ 1500) with Nikon digital sight DS-Fil camera. Size of the wound closure was measured in pixels using FiJI (NIH) software and normalized relative to $0 \mathrm{~min} \mathrm{pw}$ (immediately after injury). Each wound size was measured three times, with the values plotted on graphs representing an average from at least three embryos. Comparison of two linear mixed models was done using the R package lme4 (v1.1-21) [110] for finding the difference between conditions. Condition and time were used as fixed variables while sample type was used as a random variable.

\section{Gene expression analysis of healing tissue}

RNA-Seq experiment was designed as differential analysis of temporal expression profiles between control embryos and embryos with inhibited NO production (either using nos $1+$ nos3-MO or TRIM treatment). Embryos at stage 26 were scratched by forceps (at the middle ventral side). The tissue surrounding the wound was manually dissected, and dissected tissues from five different embryos were pooled as one biological replicate.

\section{RNA isolation}

Dissected healing tissues (red rectangle on Fig. 3a and Fig. 4a) were collected into $2 \mathrm{ml}$ tubes containing precooled beads (Qiagen Stainless Steel Beads, $5 \mathrm{~mm}$, 69, 989 ) and stored at $-80^{\circ} \mathrm{C}$ freezer. Samples were homogenized using TissueLyser LT (Qiagen) for $5 \mathrm{~min}$ at 50 $\mathrm{Hz}$. Total RNA was isolated using $1 \mathrm{ml}$ of TRI Reagent (Sigma-Aldrich, T9424) following the manufacturer's manual. The RNA pellet was then dissolved in $40 \mu \mathrm{l}$ DNAse solution $(32 \mu \mathrm{l}$ Nuclease-free water, $4 \mu \mathrm{l} 10 \mathrm{x}$ reaction buffer, $4 \mu$ l DNAse I, Sigma-Aldrich, AMPD I), and incubated at $37^{\circ} \mathrm{C}$ for $30 \mathrm{~min}$. Afterwards, $40 \mu \mathrm{l}$ of 8 M LiCl (Sigma-Aldrich, L7026) were added for RNA precipitation. This solution was incubated overnight in $-20^{\circ} \mathrm{C}$ freezer and then centrifuged for $30 \mathrm{~min}$ at 16 , $000 \mathrm{~g}$. The supernatant was removed, and the RNA was then washed twice with $1 \mathrm{ml}$ of $80 \%$ ethanol followed by centrifugation for $30 \mathrm{~min}$. The final total RNA was then diluted in $20 \mu \mathrm{l}$ of 1xTE buffer (Invitrogen, 12,090-015). The concentration of RNA was measured using Nanodrop 2000 (Thermo Scientific), and the quality of RNA was analysed using Fragment Analyzer (AATI, Standard Sensitivity RNA analysis kit, DNF-471).

\section{RNA-Seq}

\section{Library prep}

Wounded tissue samples were collected at 0, 30, 60 and 90 min pw from control and $\mathrm{NO}$ inhibited embryos and their RNA was isolated according to the protocol mentioned above. RNA-Seq experiment was performed as two separated experiments. In the first experiment, only control samples in biological triplicate were analysed. Libraries were prepared from $200 \mathrm{ng}$ of total RNA using SureSelect Strand-Specific RNA Library Prep for Illumina Multiplexed Sequencing (Agilent, G9691) according to manufacture protocol, which utilized poly-A selection of RNA. Final libraries were equimolary pooled and sequenced on NextSeq 500 using 2x75bp HighOutput mode. The data are available at NCBI's Gene Expression Omnibus [111] under GEO Series accession number GSE116667 (https://www.ncbi.nlm.nih.gov/geo/ query/acc.cgi?acc=GSE116667). The second experiment was performed similarly, where samples from both control and $\mathrm{NO}$ inhibited embryos were prepared in biological duplicates. A total of $500 \mathrm{ng}$ of total RNA was used for poly-A selection (NEB \#E7490S). The libraries were then prepared using NEBNext ${ }^{\circ}$ Ultra $^{\mathrm{Tm}}$ Directional RNA Library Prep Kit for Illumina ${ }^{\circ}$ (NEB \#E7420S) according to manufacture protocol. Again, final libraries were equimolary pooled and sequenced on NextSeq 500 using $2 \times 75 b p$ HighOutput mode and the final data has 
been deposited available under GEO Series accession number GSE116678 (https://www.ncbi.nlm.nih.gov/geo/ query/acc.cgi?acc=GSE116678).

The gene expression during tail regeneration was studied too. Tissue from the amputated tail of the stage 41 tadpoles were collected at $0,0.5,1,1.5,3,6,24,72$ and $168 \mathrm{~h}$ post amputation. RNA was then isolated and libraries prepared for RNA-Seq as similarly described for the wound healing experiment (Additional file 7: Figure S5).

\section{Data analysis}

On average, approximately $20 \mathrm{M}$ reads per sample were obtained after filtering out for low quality reads and adaptor sequence removal, using TrimmomaticPE (v. 0.36) [112] with the parameters "CROP:70 HEADCROP:15 ILLUMINACLIP: /TruSeq-PE3.fa:2:30:10 LEADING:3 TRAILING: 3 SLIDINGWINDOW:4:15 MINLEN:36". Ribosomal RNA reads were filtered out using Sortmerna (v. 2.1b) [113] (default parameters) and the cleaned reads were then aligned using STAR (v. 2.5.2b) [114] to the Xenopus laevis genome version 9.1 and annotation version 1.8.3.2 (http://www.xenbase.org/, RRID:SCR_003280) [115]. A count table was then generated using the python script htseq-count (v. 0.6.1p1) [116] with the parameter "-m union". Differentially expressed genes (DEGs) were analysed by DESeq2 (v. 1.15.51) [117] using the design formula parameter " time", with time defined as a factor. DEGs were identified using default function DESeq, with parameters "test = " LRT', reduced $=\sim 1$, fitType $=$ 'local' ${ }^{\prime}$. An expressed gene was defined as one that had a mean normalized counts of at least five, while DEGs were defined as a genes with padj $<0.1$. Similarly, to identify genes which are differentially expressed between two conditions (control vs. TRIM, control vs. nos $1+$ nos3-MO), design formula was set to " condition + time + time:condition" and parameters for DESeq function were set to "test $=$ 'LRT', reduced $=\sim$ condition, fitType $=$ local' $^{\prime \prime}$. The final list of genes was controlled manually during the clustering process.

\section{Clustering}

The optCluster (v1.1.1, R v3.4.2) package [118], using the Diana clustering method and ten requested clusters, was used to group the expression profiles of the DEGs identified from the first control experiment. Clustering was performed using the relative proportion of the averaged normalized counts across the time points. The produced ten clusters (Additional file 8: Figure S6) were then manually analysed and clusters that showed similar profiles were merged together to produce the final cluster profile (Additional file 1: File S1).

The Regularized log transformation of the normalized counts of the DEGs identified from the second experiment were clustered using degPatterns from the $\mathrm{R}$ package DEGreport (v1.13.8) [119]. The function was run using the default parameters, except that the produced clusters were allowed to contain a minimum of one gene representative $(\operatorname{minc}=1)$, similar clusters were merged based on a correlation of expression of 0.7 (cutoff $=0.7$ ) and outliers within the clusters were removed (reduce $=$ TRUE). The produced clusters $(n=36)$ (Additional file 9: Figure S7) were then manually analysed and clusters that showed similar profiles were merged together to produce the final cluster profiles (Additional file 3: File S2).

\section{Gene ontology analysis}

Gene Ontology (GO) Enrichment analysis was performed on the gene members from each unique cluster using the Gorilla webserver $[120,121]$. The biological processes were assessed using the human database as a reference, an unranked list of the human orthologues of the Xenopus laevis cluster members, and a background set containing the human orthologues for all of the Xenopus laevis genes (Additional file 10: File S3). Results were filtered to only include $p$-values less than $1 \mathrm{e}-3$. The Revigo webserver [122] was then used to summarize the significant p-value ranked GO terms as a treemap. Gene Ontology terms were collapsed if they shared 0.7 similarity while using the SimRel method to assess for similarity. The whole of the UniProt database (2017) was utilized to analyse for the size of the GO terms.

\section{RT-qPCR}

The RT-qPCR analysis was performed using $50 \mathrm{ng}$ of total RNA obtained from dissected healing tissues (red rectangle on Fig. 3a and Fig. 4a) prepared from an independent experiment (another fertilization/different female than RNA-Seq) using three biological replicates. RNA Spike I ( $0.5 \mu l$, TATAA Biocenter) was added before reverse transcription to test inhibition in enzymatic reactions. Reverse transcription was performed using SuperScript III (Invitrogen) according to the manufacturer's protocol in $10 \mu \mathrm{l}$ volume. Synthesized cDNA was diluted 10 times in 1xTE buffer and $2 \mu \mathrm{l}$ of final cDNA was added to the qPCR reaction (2x SYBRGreen mix, TATAA Biocenter, $400 \mathrm{nM}$ primers mix and Nucleasefree water to final volume $6 \mu \mathrm{l}$ ). Primer sequences are listed in the Additional file 11: Table S1. Protocol for qPCR was: $1 \mathrm{~min}$ at $95^{\circ} \mathrm{C} ; 50$ cycles of $95^{\circ} \mathrm{C}$ for $3 \mathrm{~s}$, $60^{\circ} \mathrm{C}$ for $30 \mathrm{~s}$ and $72^{\circ} \mathrm{C}$ for $10 \mathrm{~s}$; followed by melting curve analysis.

\section{In situ hybridization}

Whole-mount in situ hybridization was performed according to Sive et al. [123] protocol. List of clones which were used for analysis, their source, restriction enzyme used for linearization and RNA polymerases used for generation of RNA in sense or antisense strand can be found in Table 1. Eight healing embryos per condition 
Table 1 List of constructs and enzymes used for in situ hybridization probe preparation

\begin{tabular}{llll}
\hline Gene & Source & Antisense probe & Sense probe \\
\hline fos. S & Dharmacon & Sall, T7 & Notl, SP6 \\
& \#MXL1736-202773077 & & \\
mmp7.L & $\begin{array}{l}\text { Dharmacon } \\
\text { \#MXL1736-202774696 }\end{array}$ & Kpnl, T7 & Xhol, SP6 \\
mmp9.S & EXRC Number 851 & Xmal, T7 & Xhol, SP6 \\
& XB-CLONE-2041688 & & \\
\hline
\end{tabular}

were fixed in PFA overnight, dehydrated into methanol and stored at $-20^{\circ} \mathrm{C}$ freezer. The proteinase $\mathrm{K}$ treatment was not used. Samples were imaged on stereomicroscope (Nikon SMZ 1500) and processed using Zoner Photo Studio 17. In all cases, sense probes showed the absence of staining. Blue signal around the wound site were analysed using FiJI (NIH, v1.52n). To measure the signal, the image colour was first inverted and the intensity of the signal was then calculated using the average of the values from three independent measurements using the formula:

$$
\begin{aligned}
\text { Intensity of signal } & =\text { Integrated Density around wound } \\
& - \text { Integrated Density inside wound } \\
& -[(\text { Area around wound-Area inside wound }) * \\
& \text { Mean fluorescence of background }]
\end{aligned}
$$

The statistical difference was calculated relative to the control using GraphPad Prism 7 and One-way ANOVA with Dunnett's multiple comparisons test.

\section{Immunohistochemistry}

Five healing embryos per condition were fixed in PFA overnight, washed three times in PBT and mounted into $4 \%$ agarose diluted in water. Next, $150 \mu \mathrm{m}$ sections were prepared using Leica Vibratome (VT1000 S), and immunohistochemistry was performed according to Sive et al. [123] protocol using primary antibodies against $\beta$ catenin (1:1000, Sigma-Aldrich T9026), laminin (1:150, Sigma-Aldrich L9393) and actin - Alexa Fluor 488 phalloidin (1:1000, Life Technologies A12379). The secondary antibody Alexa 488 goat anti-rabbit (1:500, Life technologies A11008) was used for laminin and $\beta$ catenin staining. Samples were imaged using Carl Zeiss LSM 880 NLO microscope and images were processed using Zen (Zeiss) and Zoner Photo Studio 17 software.

\section{Collagens analysis}

Six embryos per condition at stage 26 were injured and fixed after $60 \mathrm{~min}$ in $4 \%$ PFA overnight. Samples were washed three times in PBS, dehydrated in $70 \%$ ethanol and embedded in paraffin. $50 \mu \mathrm{m}$ histological sections were then prepared using Leica Microtome (RM 2255) and mounted on microscope slides. Sections were deparaffined and stained using Masson's trichrome staining kit (Sigma-Aldrich, HT15). Slides were washed in demineralized water and incubated for $5 \mathrm{~min}$ in fuchsin solution. Slides were repeatedly washed in demineralized water and incubated in phosphowolfram/phosphomolybdene acid solution for $5 \mathrm{~min}$ followed by aniline blue solution for 5 minutes. Slides were then washed for 2 minutes in $1 \%$ acetic acid and dehydrated in $100 \%$ ethanol. Dehydrated samples were washed two times in 100\% xylene and covered with DPX solution (Sigma-Aldrich, 44,851). Slides were imaged using Carl Zeiss AxioZoom V16 Microscope and the images processed using Zen (Zeiss) and FiJI (NIH, v1.52n) softwares. The coverage of collagen within the wound was calculated as the length of the dark collagen layer divided by the total length of the wound. It was measured using the average from at least five slices from each embryo. The statistical significance was calculated relative to the control using GraphPad Prism 7 One-way ANOVA with Dunnett's multiple comparisons test.

\section{Supplementary information}

Supplementary information accompanies this paper at https://doi.org/10. 1186/s12864-019-6147-6.

Additional file 1. File S1 Information about various expression profiles for all genes and a complete list of enriched GO terms in Group 1 - 6

Additional file 2. Figure S1 REViGO analysis of enriched $\mathrm{GO}$ terms. Gorilla was used to determine enrichment of gene ontology terms, followed by summarization using REViGO. (A) Group 1 (B) Group 2 (C) Group 3 (D) Group 4 (E) Group 5. Similar GO terms between and within groups have the same colors

Additional file 3. File S2 Information about various expression profiles for all genes and a complete list of enriched GO terms in Group 1'-3'

Additional file 4:. Figure S2 REViGO analysis of enriched GO terms. Gorilla was used to determine enrichment of gene ontology terms, followed by summarization using REViGO. (A) Group 1' (B) Group 2' (C) Group 3'. Similar GO terms between and within groups have the same colors

Additional file 5. Figure S3 Actin staining of injury in embryos with inhibited NO production. (A) Acute NO inhibition using TRIM causes abnormal morphology of cells at the wound edge (white circle). (B) Chronic NO inhibition using MOs caused overproduction of actin around the wound edge and formation of abnormal structures inside the injury (marked by white arrows) (Scale bars $=100 \mu \mathrm{m}$ )

Additional file 6. Figure S4 Monitoring of wound closing and changes in gene expression after inhibition of $\mathrm{NO}$ pathway. (A) Scheme of NO pathway with labelled inhibitors/gene specific MO which were used in experiments. (B) Control embryos, embryos with inhibited SGC using ODQ 1 hour before injury and embryos injected with prkg1-MO were injured using a needle at stage 26. (C) Wound closing was documented using brightfield imaging on stereomicroscope. (D) Relative wound closure was calculated as the ratio between the size of the wound in 0 minute pw (E) and 30 minutes pw (at least six replicates per condition, mean with standard deviation, the statistical difference between the groups is derived from two linear mixed models). (F) RT-qPCR comparison of temporal expression profiles of fos and lep (data are normalized to 0 minutes pw in controls, three replicates, geometric mean with geometric standard deviation, two-sided t-test from log2 values of relative 
expression between inhibited samples and control in 120 minutes pw). ${ }^{* * * *}-p<.0001,{ }^{*}-p<.05$, n.s. $-p>05$. pw - post wounding Additional file 7. Figure S5 Expression of genes from the Group 4 during regeneration. Expression of genes from the Group 4 (Fig. 3h) were analyzed during regeneration of amputated tail at stage 41 using RNASeq. The same representative genes (fos - green, jun - violet, egr 1 - blue) are shown

Additional file 8. Figure S6 Complete cluster profiles of the temporal gene expression from the control embryos. Clusters were produced using the optcluster function on the relative proportion of the averaged counts across the time points. The plotted $y$-axis however represents the $z$-score of the regularized log transformation of the normalized counts

Additional file 9. Figure S7 Complete cluster profiles of the temporal gene expression from the control and NO inhibited embryos. Clusters were produced using the degPatterns function on the regularized log transformation of the normalized counts

Additional file 10. File S3 List of genes used as a background during $\mathrm{GO}$ term enrichment analysis

Additional file 11. Table S1 List of primers used for RT-QPCR

Additional file 12. Figure $\mathrm{S} 8$ Test of specificity of prkg 1-MO and lep-MO $(A, B)$ Function of MOs were analysed using RT-PCR and PCR products were visualized using gel electrophoresis. (A) Picture showed shorter product after usage of prkg1-MO. (B) Picture showed clearly that intron stayed unspliced after usage of lep-MO

Additional file 13. Figure $S 9$ Test of the effectivity of TRIM to inhibit the production of NO and for the specificity of DAF-2DA to NO. (A) Control embryos at stage 26, embryos with inhibited production of NO using TRIM (6 mM) 1 hour before injury were injured using a needle, incubated in media with DAF-2DA solution for 10 minutes, fixed and imaged. (B) The intensity of signal were analysed (t-test). (C) Similarly, tails of tadpoles at stage 41 , tadpoles with inhibited production of NO using TRIM (1 mM) or tadpoles with inihibited sGC with ODQ $(100 \mu \mathrm{M})$, were amputated and incubated in media with DAF-2DA solution for 15 minutes, fixed and imaged. (D) The intensity of signal were analysed (t-test). ${ }^{* * * *}-p<.0001$, ${ }^{* *}-p<.01,{ }^{*}-p<.05$

\section{Abbreviations}

CGMP: Cyclic guanosine monophosphate; DAF-2DA: 5,6-Diaminofluorescein diacetate; DEGs: Differentially expressed genes; GO: Gene ontology; MMPs: Matrix metalloproteinases; MO: Morpholino oligonucleotide; NO: Nitric oxide: NOS: Nitrix oxide synthase; ODQ: 1H-[1,2,4] Oxadiazolo [4,3a]quinoxalin-1-one; pa: Post amputation; PRKG1: Protein kinase cGMPdependent 1; pw: Post wounding; ROS: Reactive oxygen species; sGC: Soluble guanylate cyclase; TRIM: 1-(2-Trifluoromethylphenyl) imidazole

\section{Acknowledgements}

We acknowledge the Imaging Methods Core Facility at BIOCEV, institution supported by the Czech-Biolmaging large RI projects (LM2015062 and CZ.02.1.01/0.0/0.0/16_013/0001775, funded by MEYS CR) for their support with obtaining imaging data presented in this paper.

\section{Authors' contributions}

PA and RS designed experiments and wrote the paper. PA and ST prepared and analysed samples. PA and RN conducted bioinformatics analysis. RS and MK supervised the study. All authors read and approved submission of this manuscript.

\section{Funding}

This work was supported by RVO: 86652036; by project BIOCEV (CZ.1.05/ 1.1.00/02.0109) from the ERDF; the Grant Agency of the Czech Republic GA17-24441S. The funding bodies played no role in the design of the study and collection, analysis, and interpretation of data and in the writing of the manuscript.

\section{Availability of data and materials}

The transcriptome sequencing data from this study are available at NCBI's Gene Expression Omnibus [111] under GEO Series accession number GSE116667
(https://www.ncbi.nlm.nih.gov/geo/query/acc.cgi?acc=GSE116667) and GSE116678 (https://www.ncbi.nlm.nih.gov/geo/query/acc.cgi?acc=GSE116678).

\section{Ethics approval and consent to participate}

All animal experiments were performed in accordance with protocols approved by the animal committee of the Czech Academy of Sciences and were performed according to EU legislation (including animal handling guidelines and regulations).

\section{Consent for publication}

Not applicable.

\section{Competing interests}

The authors declare that they have no competing interests.

\section{Author details}

'Institute of Biotechnology of the Czech Academy of Sciences - BIOCEV, Prumyslova 595, 25250 Vestec, Czech Republic. ${ }^{2}$ TATAA Biocenter, Odinsgatan 28, 41103 Göteborg, Sweden.

Received: 27 May 2019 Accepted: 29 September 2019

Published online: 06 November 2019

\section{References}

1. Kim DJ, Mustoe T, Clark RA. Cutaneous wound healing in aging small mammals: a systematic review. Wound Repair Regen. 2015;23(3):318-39.

2. Guo S, Dipietro LA. Factors affecting wound healing. J Dent Res. 2010;89(3): 219-29.

3. Gupta MA, Pur DR, Vujcic B, Gupta AK. Suicidal behaviors in the dermatology patient. Clin Dermatol. 2017;35(3):302-11.

4. Sonnemann K, Bement WM. Wound repair: toward understanding and integration of single-cell and multicellular wound responses. Annu Rev Cell Dev Biol. 2011;27:237-63.

5. Thiruvoth F, Mohapatra D, Sivakumar D, Chittoria R, Nandhagopal V. Current concepts in the physiology of adult wound healing. Plastic and Aesthetic Research. 2015;2(5):250-6.

6. Reinke JM, Sorg H. Wound repair and regeneration. Eur Surg Res. 2012;49(1): 35-43.

7. Golebiewska EM, Poole AW. Platelet secretion: from haemostasis to wound healing and beyond. Blood Rev. 2015;29(3):153-62.

8. Koh TJ, DiPietro LA. Inflammation and wound healing: the role of the macrophage. Expert Rev Mol Med. 2011:13:e23.

9. Takeo M, Lee W, Ito M. Wound healing and skin regeneration. Cold Spring Harb Perspect Med. 2015;5(1):a023267.

10. Li J, Zhang S, Soto X, Woolner S, Amaya E. ERK and phosphoinositide 3kinase temporally coordinate different modes of actin-based motility during embryonic wound healing. J Cell Sci. 2013;126(Pt 21):5005-17.

11. Jacinto A, Wood W, Balayo T, Turmaine M, Martinez-Arias A, Martin P. Dynamic actin-based epithelial adhesion and cell matching during Drosophila dorsal closure. Curr Biol. 2000;10(22):1420-6.

12. Soto X, Li J, Lea R, Dubaissi E, Papalopulu N, Amaya E. Inositol kinase and its product accelerate wound healing by modulating calcium levels, rho GTPases, and F-actin assembly. Proc Natl Acad Sci U S A. 2013;110(27): 11029-34

13. Yoshii Y, Noda M, Matsuzaki T, Ihara S. Wound healing ability of Xenopus laevis embryos. I. Rapid wound closure achieved by bisectional half embryos. Develop Growth Differ. 2005:47(8):553-61.

14. Wyczalkowski MA, Varner VD, Taber LA. Computational and experimental study of the mechanics of embryonic wound healing. J Mech Behav Biomed Mater. 2013;28:125-46.

15. Baek SH, Kwon YC, Lee H, Choe KM. Rho-family small GTPases are required for cell polarization and directional sensing in Drosophila wound healing. Biochem Biophys Res Commun. 2010;394(3):488-92.

16. Danjo Y, Gipson IK. Actin 'purse string' filaments are anchored by E-cadherin-mediated adherens junctions at the leading edge of the epithelial wound, providing coordinated cell movement. J Cell Sci. 1998; 111(Pt 22):3323-32.

17. Sherratt JA. Actin aggregation and embryonic epidermal wound healing. J Math Biol. 1993;31(7):703-16. 
18. Ding Y, Colozza G, Zhang K, Moriyama Y, Ploper D, Sosa EA, et al. Genomewide analysis of dorsal and ventral transcriptomes of the Xenopus laevis gastrula. Dev Biol. 2017;426(2):176-87.

19. Gauron C, Rampon C, Bouzaffour M, Ipendey E, Teillon J, Volovitch M, et al. Sustained production of ROS triggers compensatory proliferation and is required for regeneration to proceed. Sci Rep. 2013;3:2084.

20. Love NR, Chen Y, Ishibashi S, Kritsiligkou P, Lea R, Koh Y, et al. Amputationinduced reactive oxygen species are required for successful Xenopus tadpole tail regeneration. Nat Cell Biol. 2013;15(2):222-8.

21. Xu S, Chisholm AD. C. elegans epidermal wounding induces a mitochondrial ROS burst that promotes wound repair. Dev Cell. 2017;31(1):48-60

22. Santabarbara-Ruiz P, Lopez-Santillan M, Martinez-Rodriguez I, Binagui-Casas A, Perez L, Milan M, et al. ROS-induced JNK and p38 signaling is required for unpaired cytokine activation during Drosophila regeneration. PLoS Genet. 2015;11(10):e1005595.

23. Cass DL, Sylvester KG, Yang EY, Longaker MT, Adzick NS. Wound size and gestational age modulate scar formation in fetal wound repair. J Pediatr Surg. 1997;32(3):411-5.

24. Parekh A, Hebda PA. The contractile phenotype of dermal fetal fibroblasts in Scarless wound healing. Curr Pathobiol Rep. 2017;5(3):271-7.

25. Belacortu Y, Paricio N. Drosophila as a model of wound healing and tissue regeneration in vertebrates. Dev Dyn. 2011;240(11):2379-404.

26. Chisholm AD. Epidermal wound healing in the nematode Caenorhabditis elegans. Adv Wound Care (New Rochelle). 2015;4(4):264-71.

27. Richardson R, Slanchev K, Kraus C, Knyphausen P, Eming S, Hammerschmidt M. Adult zebrafish as a model system for cutaneous wound-healing research. J Invest Dermatol. 2013;133(6):1655-65.

28. Li J, Zhang S, Amaya E. The cellular and molecular mechanisms of tissue repair and regeneration as revealed by studies in Xenopus. Regeneration (Oxf). 2016;3(4):198-208.

29. Bement WM, Mandato CA, Kirsch MN. Wound-induced assembly and closure of an actomyosin purse string in Xenopus oocytes. Curr Biol. 1999; 9(11):579-87.

30. Benink HA, Bement WM. Concentric zones of active RhoA and Cdc42 around single cell wounds. J Cell Biol. 2005;168(3):429-39.

31. Vaughan EM, You JS, Elsie Yu HY, Lasek A, Vitale N, Hornberger TA, et al. Lipid domain-dependent regulation of single-cell wound repair. Mol Biol Cell. 2014;25(12):1867-76.

32. Tu MK, Borodinsky LN. Spontaneous calcium transients manifest in the regenerating muscle and are necessary for skeletal muscle replenishment. Cell Calcium. 2014;56(1):34-41.

33. Justet C, Hernandez JA, Torriglia A, Chifflet S. Fast calcium wave inhibits excessive apoptosis during epithelial wound healing. Cell Tissue Res. 2016; 365(2):343-56.

34. Stanisstreet M. Calcium and wound healing in Xenopus early embryos. J Embryol Exp Morphol. 1982;67:195-205.

35. Kimmel HM, Grant A, Ditata J. The presence of oxygen in wound healing. Wounds. 2016;28(8):264-70.

36. Muliyil S, Narasimha M. Mitochondrial ROS regulates cytoskeletal and mitochondrial remodeling to tune cell and tissue dynamics in a model for wound healing. Dev Cell. 2014;28(3):239-52.

37. Schaffer MR, Tantry U, Gross SS, Wasserburg HL, Barbul A. Nitric oxide regulates wound healing. J Surg Res. 1996;63(1):237-40.

38. Xing Q, Zhang L, Redman T, Qi S, Zhao F. Nitric oxide regulates cell behavior on an interactive cell-derived extracellular matrix scaffold. J Biomed Mater Res A. 2015;103(12):3807-14.

39. Wood KC, Cortese-Krott MM, Kovacic JC, Noguchi A, Liu VB, Wang X, et al. Circulating blood endothelial nitric oxide synthase contributes to the regulation of systemic blood pressure and nitrite homeostasis. Arterioscler Thromb Vasc Biol. 2013;33(8):1861-71.

40. Napoli C, Paolisso G, Casamassimi A, Al-Omran M, Barbieri M, Sommese L, et al. Effects of nitric oxide on cell proliferation: novel insights. J Am Coll Cardiol. 2013;62(2):89-95.

41. Ziche M, Morbidelli L. Nitric oxide and angiogenesis. J Neuro-Oncol. 2000; 50(1-2):139-48.

42. West AR, Galloway MP, Grace AA. Regulation of striatal dopamine neurotransmission by nitric oxide: effector pathways and signaling mechanisms. Synapse. 2002;44(4):227-45.

43. Chin LC, Kumar P, Palmer JA, Rophael JA, Dolderer JH, Thomas GP, et al. The influence of nitric oxide synthase 2 on cutaneous wound angiogenesis. $\mathrm{Br}$ J Dermatol. 2011;165(6):1223-35.
44. Rigamonti E, Touvier T, Clementi E, Manfredi AA, Brunelli S, RovereQuerini P. Requirement of inducible nitric oxide synthase for skeletal muscle regeneration after acute damage. J Immunol. 2013;190(4): 1767-77.

45. Stallmeyer B, Kampfer H, Kolb N, Pfeilschifter J, Frank S. The function of nitric oxide in wound repair: inhibition of inducible nitric oxide-synthase severely impairs wound reepithelialization. J Invest Dermatol. 1999;113(6):1090-8.

46. Alderton WK, Cooper CE, Knowles RG. Nitric oxide synthases: structure, function and inhibition. Biochem J. 2001;357(Pt 3):593-615.

47. Surks HK, Mochizuki N, Kasai Y, Georgescu SP, Tang KM, Ito M, et al. Regulation of myosin phosphatase by a specific interaction with cGMPdependent protein kinase lalpha. Science. 1999;286(5444):1583-7.

48. Guzik TJ, Korbut R, Adamek-Guzik T. Nitric oxide and superoxide in inflammation and immune regulation. J Physiol Pharmacol. 2003;54(4):469-87.

49. Bartesaghi S, Radi R. Fundamentals on the biochemistry of peroxynitrite and protein tyrosine nitration. Redox Biol. 2018;14:618-25.

50. Hess DT, Matsumoto A, Kim SO, Marshall HE, Stamler JS. Protein S-nitrosylation: purview and parameters. Nat Rev Mol Cell Biol. 2005;6(2):150-66.

51. Clancy RM, Gomez PF, Abramson SB. Nitric oxide sustains nuclear factor kappaB activation in cytokine-stimulated chondrocytes. Osteoarthr Cartil. 2004;12(7):552-8.

52. Park HS, Mo JS, Choi EJ. Nitric oxide inhibits an interaction between JNK1 and C-Jun through nitrosylation. Biochem Biophys Res Commun. 2006; 351(1):281-6.

53. Thornton FJ, Schaffer MR, Witte MB, Moldawer LL, MacKay SL, Abouhamze A, et al. Enhanced collagen accumulation following direct transfection of the inducible nitric oxide synthase gene in cutaneous wounds. Biochem Biophys Res Commun. 1998;246(3):654-9.

54. Schaffer MR, Efron PA, Thornton FJ, Klingel K, Gross SS, Barbul A. Nitric oxide, an autocrine regulator of wound fibroblast synthetic function. J Immunol. 1997;158(5):2375-81.

55. Fruhbeck G. Intracellular signalling pathways activated by leptin. Biochem J. 2006;393(Pt 1):7-20.

56. Davenport NR, Sonnemann KJ, Eliceiri KW, Bement WM. Membrane dynamics during cellular wound repair. Mol Biol Cell. 2016;27(14):2272-85.

57. Chang J, Baker J, Wills A. Transcriptional dynamics of tail regeneration in Xenopus tropicalis. Genesis. 2017:55:1-2.

58. Duffield JS, Forbes SJ, Constandinou CM, Clay S, Partolina M, Vuthoori S, et al. Selective depletion of macrophages reveals distinct, opposing roles during liver injury and repair. J Clin Invest. 2005;115(1):56-65.

59. Lucas T, Waisman A, Ranjan R, Roes J, Krieg T, Muller W, et al. Differential roles of macrophages in diverse phases of skin repair. J Immunol. 2010; 184(7):3964-77.

60. Eming SA, Wynn TA, Martin P. Inflammation and metabolism in tissue repair and regeneration. Science. 2017;356(6342):1026-30.

61. LeBert D, Squirrell JM, Freisinger C, Rindy J, Golenberg N, Frecentese G, et al Damage-induced reactive oxygen species regulate vimentin and dynamic collagen-based projections to mediate wound repair. Elife. 2018;7.

62. Janda J, Nfonsam V, Calienes F, Sligh JE, Jandova J. Modulation of ROS levels in fibroblasts by altering mitochondria regulates the process of wound healing. Arch Dermatol Res. 2016;308(4):239-48.

63. Ahanger AA, Prawez S, Kumar D, Prasad R, Amarpal, Tandan SK, et al. Wound healing activity of carbon monoxide liberated from CO-releasing molecule (CO-RM). Naunyn Schmiedeberg's Arch Pharmacol. 2011;384(1):93-102.

64. Takagi T, Naito Y, Uchiyama K, Mizuhima K, Suzuki T, Horie R, et al. Carbon monoxide promotes gastric wound healing in mice via the protein kinase $C$ pathway. Free Radic Res. 2016;50(10):1098-105.

65. Liu F, Chen DD, Sun X, Xie HH, Yuan H, Jia W, et al. Hydrogen sulfide improves wound healing via restoration of endothelial progenitor cell functions and activation of angiopoietin- 1 in type 2 diabetes. Diabetes. 2014;63(5):1763-78.

66. Zhao H, Lu S, Chai J, Zhang Y, Ma X, Chen J, et al. Hydrogen sulfide improves diabetic wound healing in Ob/Ob mice via attenuating inflammation. J Diabetes Complicat. 2017;31(9):1363-9.

67. Sessa WC. Molecular control of blood flow and angiogenesis: role of nitric oxide. J Thromb Haemost. 2009;7(Suppl 1):35-7.

68. Korhonen R, Lahti A, Kankaanranta H, Moilanen E. Nitric oxide production and signaling in inflammation. Curr Drug Targets Inflamm Allergy. 2005;4(4):471-9.

69. Bosca L, Zeini M, Traves PG, Hortelano S. Nitric oxide and cell viability in inflammatory cells: a role for $\mathrm{NO}$ in macrophage function and fate. Toxicology. 2005;208(2):249-58. 
70. Coleman JW. Nitric oxide in immunity and inflammation. Int Immunopharmacol. 2001;1(8):1397-406.

71. Bogdan C. Nitric oxide and the immune response. Nat Immunol. 2001;2(10): 907-16.

72. Ferreira F, Raghunathan V, Luxardi G, Zhu K, Zhao M. Early redox activities modulate Xenopus tail regeneration. Nat Commun. 2018;9(1):4296.

73. Minns MS, Teicher G, Rich CB, Trinkaus-Randall V. Purinoreceptor P2X7 regulation of $\mathrm{Ca}(2+)$ mobilization and cytoskeletal rearrangement is required for corneal Reepithelialization after injury. Am J Pathol. 2016;186(2):285-96.

74. Leiper LJ, Walczysko P, Kucerova R, Ou J, Shanley LJ, Lawson D, et al. The roles of calcium signaling and ERK1/2 phosphorylation in a Pax6+/- mouse model of epithelial wound-healing delay. BMC Biol. 2006;4:27.

75. Han Y, Ishibashi S, Iglesias-Gonzalez J, Chen Y, Love NR, Amaya E. Ca (2+ )-induced mitochondrial ROS regulate the early embryonic cell cycle. Cell Rep. 2018;22(1):218-31.

76. Pozhitkov AE, Neme R, Domazet-Loso T, Leroux BG, Soni S, Tautz D, et al. Tracing the dynamics of gene transcripts after organismal death. Open Biol. 2017;7:1.

77. Wu YE, Pan L, Zuo Y, Li X, Hong W. Detecting activated cell populations using single-cell RNA-Seq. Neuron. 2017;96(2):313-29 e6.

78. van den Brink SC, Sage F, Vertesy A, Spanjaard B, Peterson-Maduro J, Baron $C S$, et al. Single-cell sequencing reveals dissociation-induced gene expression in tissue subpopulations. Nat Methods. 2017;14(10):935-6.

79. Tadokoro S, Ide S, Tokuyama R, Umeki H, Tatehara S, Kataoka S, et al. Leptin promotes wound healing in the skin. PLoS One. 2015;10(3):e0121242.

80. Zheng B, Jiang J, Chen Y, Lin M, Du Z, Xiao Y, et al. Leptin overexpression in bone marrow stromal cells promotes periodontal regeneration in a rat model of osteoporosis. J Periodontol. 2017:88(8):808-18.

81. Yamaguchi A, Sakuma K, Fujikawa T, Morita I. Expression of specific IGFBPs is associated with those of the proliferating and differentiating markers in regenerating rat plantaris muscle. J Physiol Sci. 2013;63(1):71-7.

82. Zhang $Y$, Proenca R, Maffei M, Barone M, Leopold L, Friedman JM. Positional cloning of the mouse obese gene and its human homologue. Nature. 1994; 372(6505):425-32

83. Mehebik N, Jaubert AM, Sabourault D, Giudicelli Y, Ribiere C. Leptininduced nitric oxide production in white adipocytes is mediated through PKA and MAP kinase activation. Am J Physiol Cell Physiol. 2005;289(2):C379-87.

84. Canabal DD, Song Z, Potian JG, Beuve A, McArdle JJ, Routh VH. Glucose, insulin, and leptin signaling pathways modulate nitric oxide synthesis in glucose-inhibited neurons in the ventromedial hypothalamus. Am J Physiol Regul Integr Comp Physiol. 2007;292(4):E1418-28.

85. Blanquicett C, Graves A, Kleinhenz DJ, Hart CM. Attenuation of signaling and nitric oxide production following prolonged leptin exposure in human aortic endothelial cells. J Investig Med. 2007;55(7):368-77.

86. Tomankova S, Abaffy P, Sindelka R. The role of nitric oxide during embryonic epidermis development of Xenopus laevis. Biol Open. 2017;6(6):862-71.

87. Ciani E, Guidi S, Bartesaghi R, Contestabile A. Nitric oxide regulates CGMPdependent CAMP-responsive element binding protein phosphorylation and $\mathrm{BCl}-2$ expression in cerebellar neurons: implication for a survival role of nitric oxide. J Neurochem. 2002;82(5):1282-9.

88. Mujoo K, Sharin VG, Martin E, Choi BK, Sloan C, Nikonoff LE, et al. Role of soluble guanylyl cyclase-cyclic GMP signaling in tumor cell proliferation. Nitric Oxide. 2010;22(1):43-50.

89. Zhang $R$, Wang $L$, Zhang $L$, Chen J, Zhu Z, Zhang Z, et al. Nitric oxide enhances angiogenesis via the synthesis of vascular endothelial growth factor and cGMP after stroke in the rat. Circ Res. 2003:92(3):308-13.

90. Schaffer MR, Tantry U, Thornton FJ, Barbul A. Inhibition of nitric oxide synthesis in wounds: pharmacology and effect on accumulation of collagen in wounds in mice. Eur J Surg. 1999;165(3):262-7.

91. Robert J, Ohta Y. Comparative and developmental study of the immune system in Xenopus. Dev Dyn. 2009;238(6):1249-70.

92. Agricola ZN, Jagpal AK, Allbee AW, Prewitt AR, Shifley ET, Rankin SA, et al. Identification of genes expressed in the migrating primitive myeloid lineage of Xenopus laevis. Dev Dyn. 2016;245(1):47-55.

93. Briggs JA, Weinreb C, Wagner DE, Megason S, Peshkin L, Kirschner MW, et al. The dynamics of gene expression in vertebrate embryogenesis at single-cell resolution. Science. 2018;360:6392.

94. Harrison M, Abu-Elmagd M, Grocott T, Yates C, Gavrilovic J, Wheeler GN. Matrix metalloproteinase genes in Xenopus development. Dev Dyn. 2004; 231(1):214-20.
95. Tomlinson ML, Garcia-Morales C, Abu-Elmagd M, Wheeler GN. Three matrix metalloproteinases are required in vivo for macrophage migration during embryonic development. Mech Dev. 2008;125(11-12):1059-70.

96. Caley MP, Martins VL, O'Toole EA. Metalloproteinases and wound healing. Adv Wound Care (New Rochelle). 2015;4(4):225-34.

97. Sudbeck BD, Pilcher BK, Welgus HG, Parks WC. Induction and repression of collagenase- 1 by keratinocytes is controlled by distinct components of different extracellular matrix compartments. J Biol Chem. 1997;272(35): 22103-10.

98. Danielsen PL, Holst AV, Maltesen HR, Bassi MR, Holst PJ, Heinemeier KM, et al. Matrix metalloproteinase-8 overexpression prevents proper tissue repair. Surgery. 2011;150(5):897-906.

99. Witte MB, Kiyama T, Barbul A. Nitric oxide enhances experimental wound healing in diabetes. Br J Surg. 2002;89(12):1594-601.

100. Blecher K, Martinez LR, Tuckman-Vernon C, Nacharaju P, Schairer D, Chouake J, et al. Nitric oxide-releasing nanoparticles accelerate wound healing in NOD-SCID mice. Nanomedicine. 2012;8(8):1364-71.

101. Spitler R, Schwappacher R, Wu T, Kong X, Yokomori K, Pilz RB, et al. Nitrosyl-cobinamide (NO-Cbi), a new nitric oxide donor, improves wound healing through cGMP/CGMP-dependent protein kinase. Cell Signal. 2013;25(12):2374-82.

102. Han G, Nguyen LN, Macherla C, Chi Y, Friedman JM, Nosanchuk JD, et al. Nitric oxide-releasing nanoparticles accelerate wound healing by promoting fibroblast migration and collagen deposition. Am J Pathol. 2012;180(4): 1465-73.

103. Gursoy K, Oruc M, Kankaya Y, Ulusoy MG, Kocer U, Kankaya D, et al. Effect of topically applied sildenafil citrate on wound healing: experimental study. Bosn J Basic Med Sci. 2014;14(3):125-31.

104. Yang T, Zelikin AN, Chandrawati R. Progress and promise of nitric oxidereleasing platforms. Adv Sci (Weinh). 2018;5(6):1701043.

105. Saidkhani V, Asadizaker M, Khodayar MJ, Latifi SM. The effect of nitric oxide releasing cream on healing pressure ulcers. Iran J Nurs Midwifery Res. 2016; 21(3):322-30.

106. Edmonds ME, Bodansky HJ, Boulton AJM, Chadwick PJ, Dang CN, D'Costa R, et al. Multicenter, randomized controlled, observer-blinded study of a nitric oxide generating treatment in foot ulcers of patients with diabetesProNOx1 study. Wound Repair Regen. 2018;26(2):228-37.

107. Smith JC, Slack JM. Dorsalization and neural induction: properties of the organizer in Xenopus laevis. J Embryol Exp Morphol. 1983;78:299-317.

108. Nieuwkoop PD, Faber J. Normal table of Xenopus laevis (Daudin): a systematical and chronological survey of the development from the fertilized egg till the end of metamorphosis: Garland Publishing Inc.; 1994.

109. Jacox L, Sindelka R, Chen J, Rothman A, Dickinson A, Sive H. The extreme anterior domain is an essential craniofacial organizer acting through KininKallikrein signaling. Cell Rep. 2014;8(2):596-609.

110. Douglas B, Maechler M, Bolker B, Walker S. Fitting linear mixed-effects models using Ime4. J Stat Softw. 2015;67(1):1-48.

111. Edgar R, Domrachev M, Lash AE. Gene expression omnibus: NCBI gene expression and hybridization array data repository. Nucleic Acids Res. 2002;30(1):207-10

112. Bolger AM, Lohse M, Usadel B. Trimmomatic: a flexible trimmer for Illumina sequence data. Bioinformatics. 2014;30(15):2114-20.

113. Kopylova $E$, Noe L, Touzet $H$. SortMeRNA: fast and accurate filtering of ribosomal RNAs in metatranscriptomic data. Bioinformatics. 2012;28(24):3211-7.

114. Dobin A, Davis CA, Schlesinger F, Drenkow J, Zaleski C, Jha S, et al. STAR: ultrafast universal RNA-seq aligner. Bioinformatics. 2013;29(1):15-21.

115. Karimi K, Fortriede JD, Lotay VS, Burns KA, Wang DZ, Fisher ME, et al. Xenbase: a genomic, epigenomic and transcriptomic model organism database. Nucleic Acids Res. 2018:46(D1):D861-8.

116. Anders S, McCarthy DJ, Chen Y, Okoniewski M, Smyth GK, Huber W, et al. Count-based differential expression analysis of RNA sequencing data using $\mathrm{R}$ and bioconductor. Nat Protoc. 2013;8(9):1765-86.

117. Love Ml, Huber W, Anders S. Moderated estimation of fold change and dispersion for RNA-seq data with DESeq2. Genome Biol. 2014;15(12):550.

118. Sekula M, Datta S, Datta S. optCluster: an R package for determining the optimal clustering algorithm. Bioinformation. 2017;13(3):101-3.

119. Panatano L. DEGreport: report of DEG analysis; 2017.

120. Eden E, Navon R, Steinfeld I, Lipson D, Yakhini Z. GOrilla: a tool for discovery and visualization of enriched $\mathrm{GO}$ terms in ranked gene lists. BMC Bioinformatics. 2009;10:48. 
121. Eden E, Lipson D, Yogev S, Yakhini Z. Discovering motifs in ranked lists of DNA sequences. PLoS Comput Biol. 2007;3(3):e39.

122. Supek F, Bosnjak M, Skunca N, Smuc T. REVIGO summarizes and visualizes long lists of gene ontology terms. PLoS One. 2011;6(7):e21800.

123. Sive HL, Grainger RM, Harland RM. Early development of Xenopus laevis: a laboratory manual. New York: cold Spring Harbor laboratory press; 2000.

\section{Publisher's Note}

Springer Nature remains neutral with regard to jurisdictional claims in published maps and institutional affiliations.

\section{Ready to submit your research? Choose BMC and benefit from:}

- fast, convenient online submission

- thorough peer review by experienced researchers in your field

- rapid publication on acceptance

- support for research data, including large and complex data types

- gold Open Access which fosters wider collaboration and increased citations

- maximum visibility for your research: over $100 \mathrm{M}$ website views per year

At $\mathrm{BMC}$, research is always in progress. 